\title{
LAS EMPRESAS DE INSERCIÓN SOCIOLABORAL Y LAS CLÁUSULAS SOCIALES EN LA CONTRATACIÓN PÚBLICA: DOS INSTRUMENTOS NECESARIOS PARA LA INNOVACIÓN SOCIAL HACIA EL DESARROLLO
}

\author{
POR \\ Manuel PANIAGUA ZURERA*
}

\section{RESUMEN}

La innovación social orientada al desarrollo personal y comunitario constituye una nueva materia objeto de análisis multidisciplinares. De su utilidad da muestras la Unión Europea que la ha incluido en sus objetivos de crecimiento económico y de empleo (Estrategia Europea 2020). La investigación analiza dos instrumentos, interrelacionados, ubicados en los temas de la innovación social y de la economía social. Primero, el principal agente de la nueva economía social: las empresas de inserción sociolaboral y sus entidades no lucrativas promotoras, que cuentan en España con una legislación específica o ad hoc. Aportamos elementos para la categorización jurídica y económica de estos nuevos empresarios, cuya alma es un fin social y de interés general (la inserción sociolaboral de personas excluidas). En segundo lugar, justificamos la demanda de mercados sociales para nuestras empresas de inserción. Los razonamientos económicos y jurídicos coinciden en la conveniencia (por su eficiencia económica), la legitimidad (por su conformidad con los valores que presiden el Derecho comunitario y el de sus Estados miembros) y la legalidad de

\footnotetext{
Profesor Titular de Área de Derecho Mercantil. UNIVERSIDAD LOYOLA ANDALUCÍA. Campus de Córdoba. Dirección de correo electrónico: paniagua@etea.com y paniagua@uloyola.es

Esta investigación se enmarca dentro del Proyecto de Investigación de Excelencia de la Junta de Andalucía " $\mathrm{La}$ protección de los consumidores como ariete de la reforma de la empresa, las reglas de competencia y la cultura empresarial" (SEJ-P10-6073), cuyo investigador principal es el Prof. Dr. Javier López Pagador. Y en el marco del Proyecto del Ministerio de Ciencia e Innovación (DER 2010-16204), cuyo investigador principal es el Prof. Dr. Luis María Miranda Serrano.
}

REVESCO No 112 - Extraordinario en Homenaje al Profesor Alfonso Carlos MORALES GUTIÉRREZ - ISSN: 1885-8031 - www.ucm.es/info/revesco

http://dx.doi.org/10.5209/rev_REVE.2013.v112.43066

Fecha de recepción: 22/04/2013

Fecha de aceptación: 20/09/2013 
las cláusulas o los criterios sociales en la contratación del sector público. Avanzamos la interpretación de estos criterios sociales más conforme con el Derecho comunitario y español, que no siempre ha tenido como aliado a la Comisión Europea y sus propuestas neoliberales.

Palabras clave: Empresas de inserción, Exclusión social, Economía social, Políticas activas de empleo, Criterios sociales en la contratación del sector público, Estado social.

Claves Econlit: L26, D23, D60, J64, L31, I31.

\title{
INSERTION ENTERPRISES AND SOCIAL CLAUSES IN PUBLIC CONTRACTS: TWO NECESSARY INSTRUMENTS IN SOCIAL INNOVATION FOR DEVELOPMENT
}

\begin{abstract}
Social innovation oriented towards personal and community development is a new topic that is the object of multidisciplinary analysis. The European Union shows how useful it is by including social innovation in its objectives for economic and employment growth (European Strategy 2020). Our research analyses two interrelated instruments within the framework of social innovation and social economy. First, the main agent in the new social economy: insertion enterprises and their non-profit entities, which have specific legislation in Spain. We contribute elements for the legal and economic classification of these new entrepreneurs, whose guiding spirit is a social objective and of general interest (the social and labor integration of those excluded). Secondly, we justify the demand for social markets for our insertion enterprises. Economic and legal reasons coincide in their suitability (due to their economic efficiency), legitimacy (as they comply with the values that prevail in the European Union law and in the law of member States) and legality in terms of the social criteria used in hiring in the public sector. We present the interpretation of these social criteria more in line with European Union and Spanish law, which has not always counted on the European Commission and its neoliberal proposals as allies.
\end{abstract}

Key words: Insertion enterprises, Social exclusion, Social economy, Active employment policies, Social clauses in public contracts, Welfare State.

REVESCO No 112 - Extraordinario en Homenaje al Profesor Alfonso Carlos MORALES

GUTIÉRREZ - ISSN: 1885-8031 - www.ucm.es/info/revesco 


\section{LA INNOVACIÓN SOCIAL AL SERVICIO DE LA INCLUSIÓN SOCIOLABORAL DE PERSONAS ESPECIALMENTE DESFAVORECIDAS}

A) La preocupación por la innovación social comprometida con la dignidad y el desarrollo humano en el pensamiento del Profesor Alfonso C. Morales

Tras décadas de afanoso y fructífero trabajo en las materias de cooperación y de economía social (ad ex., MORALES GUTIÉRREZ, 1991 y 2006), de análisis y diseño de sistemas organizativos y de dirección de personal (ad ex., MORALES GUTIÉRREZ, 1995 y 2000), el talento y la creatividad del Prof. Alfonso C. Morales arribó a una nueva parcela de conocimiento multidisciplinar en construcción: la innovación social como instrumento de desarrollo personal y social (ad ex., MORALES GUTIÉRREZ, 2008 y 2009).

En sus últimos años de rica producción intelectual le cautivó el fenómeno de la innovación social como proceso clave en las bruscas transformaciones que sacuden a las actuales sociedades globalizadas, desorientadas y desestructuradas, a los anémicos Estados sociales en el primer mundo y a las desbordadas organizaciones privadas de asistencia y servicios sociales, a las economías de mercado o capitalistas y sus derivas neoliberales fundamentalistas, a los distintos tipos de empresas y empresarios y, por supuesto, al tercer sector o economía social y sus retos presentes (v. gr., la noción, los agentes, los valores, los problemas de viabilidad y de identidad y la preservación de su función social y de interés general).

No causa sorpresa que su última gran obra digital, el blog "cerillas en la oscuridad", esté dedicado a la innovación social ${ }^{1}$. El título de blog lo toma de un viejo proverbio chino que le sirve de pórtico: "Cuando llega la noche más vale encender una cerilla que maldecir la oscuridad". En este pensamiento bien puede condensarse la actitud hacia la acción, la creación, la colaboración y el compromiso personal y social que presidió la obra y la vida de Alfonso C. MORALES.

Sin olvidar el carácter tentativo y multidisciplinar que todavía hoy tienen los avances en innovación social, a su entender este nuevo hecho puede caracterizarse, de entrada y en parte, con estas notas predicadas de cierta forma colectiva de actividad humana: $1^{\text {a }}$ ) Una acción de desarrollo social que surge de las personas necesitadas para mejorar su bienestar. $2^{\mathrm{a}}$ )

\footnotetext{
${ }^{1}$ Vid http://cerillasenlaoscuridad.blogspot.com. 
Una acción original o creativa que genera un cambio en la prestación de bienes o servicios, en sentido amplio (p. ej., nuevos métodos para la prestación de bienes o de servicios o nuevos productos o servicios para satisfacer necesidades sociales). Y, $3^{\text {a }}$ ) Una acción reproducible, es más, que tiende a su difusión como buena causa o práctica, o ambas.

Confiaba en que los resultados de esta modalidad de innovación social que es la dirigida a la mejora del desarrollo personal y social (v. gr., los microcréditos y otros instrumentos de inversión socialmente responsables, las certificaciones y los balances sociales, los bancos de tiempo, el comercio justo, los presupuestos participativos, las asociaciones de interés general y las fundaciones, el voluntariado social, las cláusulas o criterios sociales en la contratación pública o las empresas de inserción sociolaboral), tuviesen como naturales y útiles aliados a los avances tecnológicos en informática y en comunicación (MORALES GUTIÉRREZ, 2008 y 2009). Por otro lado, no olvidaba el importante papel que las universidades y los centros de formación e investigación debían jugar como artífices de procesos de innovación social y de su difusión (MORALES GUTIÉRREZ, ARIZA MONTES y MUÑIZ RODRÍGUEZ, 2012: 158-159). Estas intuiciones y presentimientos, resultado de un trabajo de atenta observación de la realidad, han sido confirmados por la propia Unión Europea (PANIAGUA ZURERA, 2011-a) ${ }^{2}$.

Esta propuesta de comprensión amplia, o intencionalmente abierta, de la innovación social hacia el desarrollo debe completarse con sus diferencias respecto a las innovaciones o creaciones originales literarias, artísticas o científicas (amparadas por la propiedad intelectual, en nuestra cultura jurídica), de un lado, y las invenciones industriales y los signos distintivos (protegidas por la propiedad industrial), de otro. En primer lugar, las actividades y los

\footnotetext{
${ }^{2}$ Vid, de un lado, los dictámenes del Comité Económico y Social Europeo (CESE) sobre el "Espíritu empresarial social y las empresas sociales" (Dictamen exploratorio solicitado por la Comisión Europea) (DOUE C 24, de 28 de enero de 2012); y sobre la Comunicación de la Comisión (sic) "Iniciativa a favor del emprendimiento social. Construir un ecosistema para promover las empresas sociales en el centro de la economía y la innovación sociales" (DOUE C 229, de 31 de julio de 2012). Y, por otro, la citada Comunicación de la Comisión Europea al Parlamento Europeo, al Consejo, al CESE y al Comité de las Regiones, COM (2011) 682 final, de 25 de octubre de 2011; y, la propuesta de Reglamento del Parlamento Europeo y del Consejo relativo a un "Programa de la Unión Europea para el Cambio y la Innovación Sociales", COM (2011) 609 final, de 6 de octubre de 2011. Todo éste, por ahora, soft law comunitario forma parte de la nueva estrategia económica para la próxima década: Europa 2020 que sustituye a la estrategia de Lisboa. Uno de los ejes de esta (sic) "visión de la economía social de mercado de Europa para el siglo XXI", es el desarrollo de una economía basada en el conocimiento y la innovación (crecimiento inteligente), otro es el fomento de una economía con altos niveles de empleo dotada de cohesión social y territorial (crecimiento integrador), y el tercero es un crecimiento sostenible. Vid la Comunicación de la Comisión Europea "Europa 2020. Una estrategia para un crecimiento inteligente, sostenible e integrador", COM (2010) 2020 final, de 3 de marzo de 2010. La documentación citada puede consultarse en www.europa.eu/eu-law.
} 
resultados de la innovación social orientada al desarrollo se dirigen a la resolución de problemas sociales, usualmente unidos a las necesidades humanas básicas (v. gr., la subsistencia, la vivienda, la sanidad, el empleo, otros servicios sociales básicos o la integración social), y no a la creación $-\mathrm{y}$, posterior empleo en la producción y comercialización- de nuevos bienes, servicios o procedimientos industriales o comerciales. En segundo lugar, los referidos procesos y sus efectos son intensivos en el uso de capital humano y relacional (de ahí su interés para las estrategias de lucha contra la pobreza y la exclusión social), y no tanto de recursos financieros, normalmente ajenos. Y, en tercer lugar, los evocados instrumentos o mecanismos y sus efectos o rendimientos surgen y se difunden para ser imitados y reproducidos (y, si es posible, para generar una colaboración en red), no para su protección temporal o, en algún caso, tendencialmente indefinida, mediante derechos de explotación económica en exclusiva o en régimen de monopolio.

Pero, para el maestro MORALES GUTIÉRREZ la innovación social hacia el desarrollo que debe promoverse es la "fundada en valores", que es el enfoque coherente con "su filosofía". Donde la innovación social sirve a un fin, a una causa o, quizá mejor, se pone al servicio de unos valores en perspectiva ética y de servicio al bien común, el hoy denominado "interés general". Como, en forma muy destacada, los valores inherentes al desarrollo de la dignidad humana y los avances en igualdad real y hacia la justicia en sentido amplio y material ${ }^{3}$ (DWORKIN, 1995; SEN, 2010; PÉREZ LUÑO, 2011). Este contenido axiológico no tiene, conviene advertirlo, ni elementos idénticos, ni el mismo grado de maduración y explicitación en todos los procesos de innovación social para el desarrollo ${ }^{4}$; pero, los referidos metavalores están en la cimentación ético-ideológica de todos estos procesos $^{5}$. La implementación de estos valores (y los específicos de cada modalidad de la

\footnotetext{
${ }^{3}$ Hacemos referencia a una visión ética que rechazando la posesión definitiva de la verdad, hoy representada en especial por el sofisma neoliberal, agranda o apertura tanto la percepción de la realidad (digamos, educa la mirada, en expresión grata a nuestro maestro el Prof. Juan I. FONT GALÁN), como orienta y disciplina el comportamiento (el humilde compromiso con la transformación de la realidad en sus muchos aspectos y estructuras fallidas). La complacencia, incluso la connivencia (HAYEK, 2006), con una realidad domina por las fuerzas económicas y gestionada a favor de sus intereses, no es la propia de esta mirada.

${ }^{4}$ Cfr., ad exemplum, los valores y los principios cooperativos reformulados por el $31^{\circ}$ Congreso de la Alianza Cooperativa Internacional (ACI) en Manchester en 1995 y la Carta de principios de la economía social aprobada en junio de 2002 por la Conferencia Europea Permanente de cooperativas, mutualidades, asociaciones y fundaciones (CEP-CMAF), que desde 2008 ha pasado a denominarse Social Economy Europe (SEE). Y, por ejemplo, la Declaración Universal sobre Voluntariado aprobada por la Asociación Internacional de Esfuerzos Voluntarios (IAVE) en su Congreso Mundial LIVE'90, en París. La documentación citada puede consultarse en www.ica.coop.es; www.socialeconomy.eu.org; y www.iave.org.

${ }^{5}$ Por ejemplo, el CESE une las empresas sociales y la innovación social a metas como la mejora de la calidad de vida de los ciudadanos y la satisfacción de nuevas necesidades de la sociedad (CESE, 2011). Por su parte, la
}

REVESCO No 112 - Extraordinario en Homenaje al Profesor Alfonso Carlos MORALES

GUTIÉRREZ - ISSN: 1885-8031 - www.ucm.es/info/revesco 
referida innovación) es el parámetro básico para analizar y enjuiciar a esta innovación social, y sus contenidos y sus resultados son materiales de análisis pluridisciplinar. En este juicio hemos de atender tanto a la suma de cambios en las personas (p. ej., el respeto y desarrollo de la dignidad humana y sus derechos inherentes, el incremento de la autoestima, la apertura al mundo o la mejora en habilidades dirigidas a la gestión de recursos), como a las mejoras en las relaciones sociales (p. ej., la mayor cohesión social, la participación social e institucional efectiva, la reducción de desigualdades, la generación de oportunidades de ascenso social o el incremento de las capacidades colectivas).

No debemos ocultar que existe otro enfoque de la innovación social para el desarrollo personal y social. Es la perspectiva neoliberal para la que este tipo de innovación social como en general los avances científicos, tecnológicos y de innovación- son simples medios para la generación exógena de cambios, cuyo primer y principal criterio de valoración es la eficiencia económica medida en términos de estrictos beneficios económicos. Los nutridísimos casos de innovación social liberal y neoliberal van desde las nuevas formas de organización del trabajo que tanto han contribuido al bienestar general (v. gr., las primeras fábricas, el fordismo o el taylorismo, incluido el digital), hasta recientes fenómenos abusivos de ingeniería política, económica, jurídica y financiera que tanto daño han ocasionado a unas economías interdependientes o globalizadas (p. ej., el dumping social, los modelos de agencia, el forum shopping legislativo, las burbujas inmobiliarias y financieras, los paraísos normativos y fiscales y, tristemente para los Estados democráticos, los nuevos mecanismos de corrupción político-económica). Si los resultados de esta innovación social neoliberal no incrementan el porcentaje de beneficios (individuales) respecto a otras inversiones alternativas, el fruto obtenido -por muy interesante que resulte para el interés general o el bien común- pasa desapercibido a esta mirada neoliberal, pues no es eficiente para, y funcional a, los valores del mercado (el beneficio, el individualismo, el egoísmo o el utilitarismo) (PANIAGUA ZURERA, 2011-b). Cuando, y conviene subrayarlo, tanto la Moral como el mismo gasto social son presupuestos necesarios para el funcionamiento del mercado tal y como lo entendemos.

Comisión Europea sitúa a la economía social y a la innovación social en el centro de sus iniciativas para la cohesión territorial, la búsqueda de soluciones originales para los problemas sociales y, en especial, la lucha contra la pobreza y la exclusión. Respecto a la empresa social afirma que sus organizaciones se basan en principios democráticos o participativos (sic) "u orientados a la justicia social, son reflejo de su misión" (COMISIÓN, 2011). La documentación citada puede consultarse en www.europa.eu. 
B) El Año europeo de la creatividad y la innovación, seguido por el Año europeo de lucha contra la pobreza y la exclusión social

El año 2009 fue declarado “Año Europeo de la Creatividad y la Innovación” por la Unión Europea ${ }^{6}$. El objetivo general de este Año Europeo fue respaldar los esfuerzos de los Estados miembros "para promover la creatividad por medio del aprendizaje permanente, como motor de la innovación y como factor clave del desarrollo de las competencias personales, laborales, empresariales y sociales de todos los individuos en la sociedad, así como de su bienestar social” (art. 2.1 Decisión 1350/2008/CE).

Entre los objetivos específicos figuran algunas referencias inconexas a la innovación social y, específicamente, a la innovación social para el desarrollo. El citado año debía prestar atención, de un lado, a "todas las formas de innovación, incluida la innovación social y empresarial" (art. 2.2 letra a) y, de otro, al fomento del empleo y del "espíritu empresarial, especialmente entre los jóvenes, mediante la cooperación con el mundo de la empresa" (art. 2.2 letra d).

Al año siguiente la innovación social fue llamada para alcanzar uno de los principales objetivos que la propia Unión Europea se autoimpuso como parte de la Estrategia de Lisboa (2000): los Jefes de Estado y de Gobierno de la Unión acordaron convertir la lucha contra la pobreza y contra la exclusión social en uno de "los elementos centrales de la modernización del modelo social europeo" ". Sin ningún éxito, como hoy conocemos, se pidió a los Estados miembros medidas con un impacto decisivo en la erradicación de la pobreza a más tardar en 2010. Este Consejo Europeo empleó estas lapidarias palabras, que estimamos suscriben toda la ciudadanía europea (no así todos los Legislativos y Gobiernos europeos): “Es inaceptable el número de personas que viven en la Unión por debajo del umbral de la pobreza y excluidas socialmente”, y añadía que "la mejor salvaguardia contra la exclusión social es el trabajo".

\footnotetext{
${ }^{6}$ Vid la Propuesta presentada por la Comisión de Decisión del Parlamento Europeo y del Consejo relativa al referido Año Europeo [COM (2008) 159 final, de 28 de marzo de 2008]; y, la Decisión 1350/2008/CE del Parlamento Europeo y del Consejo, de 16 de diciembre de 2008, relativa al Año Europeo de la Creatividad y la Innovación 2009 (DOUE L 348, de 24 de diciembre de 2008). La documentación citada puede consultarse en www.europa.eu.

${ }^{7}$ Es oportuno recordar, especialmente en estos tiempos tras el vendaval neoliberal y la persistencia de la Gran Recesión, que el modelo social europeo se caracteriza, singularmente, por este tridente cultural y convivencial: la existencia de unos sistemas de protección social de elevado nivel y calidad, la importancia del diálogo y el consenso social, y unos servicios de interés general que comprenden actividades y prestaciones esenciales para la cohesión social (PANIAGUA ZURERA, 2011-a).
} 
La Recomendación de la Comisión de 3 de octubre de 2008 sobre la inclusión activa de las personas excluidas del mercado laboral ${ }^{8}$, ya en plena Gran Recesión, insistió en la necesidad de aplicar una estrategia global para la integración de estas personas combinando tres medidas: un apoyo a la renta adecuado para llevar una vida digna, unos mercados de trabajo inclusivos que fomenten empleos de calidad y un acceso a unos servicios de calidad mediante un apoyo social adecuado.

De poco sirvió, de ahí que en la Decisión del Parlamento Europeo y del Consejo sobre el Año Europeo de lucha contra la pobreza y la exclusión social $(2010)^{9}$, se insista en que, a pesar de los logros, "gran parte de la población sigue sufriendo privaciones o un acceso limitado y desigual a los servicios o está excluida de la sociedad”. Los objetivos y principios directores de este Año Europeo fueron: $1^{\circ}$ ) El reconocimiento del derecho fundamental de las personas que se encuentren en situación de pobreza y exclusión social a vivir con dignidad y desempeñar un papel activo en la sociedad; $2^{\circ}$ ) El aumento del compromiso y la responsabilidad de los actores públicos y privados en la lucha contra la pobreza y la exclusión social; $3^{\circ}$ ) La promoción de una sociedad más solidaria, más sensibilizada en la lucha contra la pobreza y la exclusión social, que apoye y desarrolle la calidad de vida, "incluida la calidad de las cualificaciones y del empleo"; y 4º El compromiso de la Unión Europea y de los Estados miembros de influir decisivamente en la erradicación de la pobreza y la exclusión social y obtener un mayor impulso en sus acciones de protección social y de inclusión social (art. 2.1). Las declaraciones y las recomendaciones institucionales se suceden, pero falta la necesaria voluntad política y, por supuesto, la imprescindible presión social, para transformar esta realidad de pobreza y exclusión social en la Europa desarrollada.

\section{C) La dramática paradoja de la exclusión social en el primer mundo}

Una de las heridas más sangrantes de los fallos de mercado ${ }^{10} \mathrm{y}$, también de los fallos de gobierno en sentido amplio (Estados nacionales, organizaciones supranacionales y

\footnotetext{
${ }^{8}$ DOUE L 307, de 18 de noviembre de 2008.

${ }^{9}$ Decisión 1098/2008/CE del Parlamento Europeo y del Consejo, de 22 de octubre de 2008, relativa al Año Europeo de Lucha contra la Pobreza y la Exclusión Social (2010) (DOUE L 298, 7.11.2008).

${ }^{10}$ La doctrina económica dominante, la denominada con evidente imprecisión como doctrina neoclásica, minimiza o ningunea estos fallos del mercado, y cínicamente sacrifica a los afectados (p. ej., los desempleados o los excluidos sociales) en el altar del mercado eficiente. Con grosería se oculta, en primer lugar, que sin la acción de los Estados y sus instituciones no existirían mercados y, en segundo lugar, que sin la regulación, el control y la defensa de los mercados los agentes económicos, y principalmente los empresarios y profesionales, acaban
}

REVESCO Nº 112 - Extraordinario en Homenaje al Profesor Alfonso Carlos MORALES

GUTIÉRREZ - ISSN: 1885-8031 - www.ucm.es/info/revesco 
organismos internacionales), es el drama de la exclusión social en los Estados altamente desarrollados: la existencia de un cuarto mundo, constituido por los pobres y los excluidos del primer mundo. ¿Cómo hemos retrocedido tanto en tan poco tiempo, especialmente en los Estados del bienestar de la Europa occidental? Aportemos unos mínimos elementos de reflexión y análisis a este interrogante que, con reiteración, oímos y leemos hoy.

Desde la Segunda Guerra Mundial y hasta la crisis del petróleo (1973-1974) asistimos, con el beneplácito social, económico y político (incluido el de los Estados nacionales hegemónicos y los organismos internacionales de cooperación económica), a una creciente intervención pública en las desarrolladas economías capitalistas o de mercado que la doctrina económica -por aquel entonces con un enfoque keynesiano mayoritario- identifica y apela como economías mixtas, por la creación de un potente sector público junto al tradicional sector privado y sus interrelaciones, especialmente de rivalidad y de competencia, pero sin que falten las de colaboración. Para describir esta misma realidad los juristas y los politólogos suelen unir, a la conquista del Estado democrático en el periodo de entreguerras mundiales, la aparición del Estado social, cuyos primeros avances se ubican en la Europa más desarrollada desde finales del siglo XIX (v. gr., Alemania y Reino Unido). El gran desarrollo experimentado por Europa occidental en la segunda posguerra mundial hizo posible alcanzar el pleno empleo (el mayor logro socioeconómico) y consensuar la redistribución de unos crecientes ingresos públicos (un no menor logro ideológico-político). En este escenario de bonanza económica, de paz social y de colaboración política, los Estados sociales de la Europa occidental desembocaron en los Estados del bienestar, pues hubo -y, hay- varios modelos históricos (FONT GALÁN, 1987; SOTELO, 2010; FONT OPORTO, 2012).

A raíz de la aludida crisis económica de comienzos de los setenta, una más de las crisis cíclicas de las economías de mercado, asistimos a la paradoja de que en lugar de redoblar los esfuerzos y las políticas macroeconómicas anticíclicas tradicionales, se abre paso

matando por asfixia a su razón de ser: la competencia económica (FONT GALÁN, 1987; SEN, 2010; RODRIK, 2012; SANDEL, 2013).

Reparemos, por otra parte, que la doctrina neoclásica en un sentido amplio (si se nos permite la simplificación, la que apoya la ciencia económica en los métodos cuantitativos) acoge variantes bien diversas. Por ejemplo, a su digamos izquierda política se sentarían los partidarios de una necesaria regulación de los mercados y de unas necesarias intervenciones públicas (p. ej., A. Sen o J. E. Stiglitz). Mientras a su derecha política se acomodarían los apelados como ortodoxos, fundamentalistas o monetaristas (p. ej., G. Stigler o M. Friedman), que propugnan la mínima intervención estatal y la máxima desregulación de los mercados a favor de una libertad que la Gran Recesión ha desvelado que raya el libertinaje económico y la irresponsabilidad económica, social, jurídica y, por supuesto, ética.

REVESCO No 112 - Extraordinario en Homenaje al Profesor Alfonso Carlos MORALES

GUTIÉRREZ - ISSN: 1885-8031 - www.ucm.es/info/revesco 
una inflexible corriente ideológica y política (neoconservadora) y socioeconómica (neoliberal) que desacredita las soluciones neokeynesianas, y que había permanecido larvada desde finales de los cincuenta de la pasada centuria. El punto de arranque no fue la oferta de nuevas salidas o remedios antricrisis, sino de facto la vuelta al liberalismo sin trabas del siglo XIX. La estrategia, pues fue diseñada como tal ${ }^{11}$, se apoyo en dos procesos, digamos, uno de demolición y otro de sustitución. Con el primero se cuestionó la idoneidad de la intervención pública en la economía para alcanzar los tres objetivos macroeconómicos fundamentales: la corrección de los defectos en la asignación de los recursos derivados de fallos en el funcionamiento de los mercados, la redistribución de las rentas asignadas por los mecanismos de los mercados y el impulso de un crecimiento económico sostenido y estable que haga compatible la estabilidad de precios y el pleno empleo. No sólo se devaluó, y desacreditó, la bondad de la intervención pública en la economía, sino que interesadamente se publicitó que este intervencionismo era la mayor dificultad para alcanzar los citados objetivos. Se reiteraba con tesón que la mejor gestión era la proporcionada por la iniciativa privada, no la procedente de los gobiernos, que debían limitarse simplemente a mantener a raya la inflación con medidas de política monetaria.

El segundo golpe fue más demoledor, pues ofreció unos remedios tan fáciles y parciales, como letales en lo económico e insolidarios en lo social. Por ejemplo, pensemos en la acción combinada de estas cuatro recetas neoliberales. Primera, la liberalización y la promoción -esto es, el fomento público, aunque se oculte bajo variados ropajes y eufemismos $^{12}$ - de las fuerzas económicas, en manos de unas escasas -por las sucesivas concentraciones- élites político-económicas. Segunda, la reducción a su mínima expresión de la directa intervención estatal en la economía (la privatización del sector público) y en la sociedad (la desregulación de los mercados, y la reducción de los servicios de interés general y de las políticas sociales). Tercera, la eliminación de todo tipo de trabas, cargas y costes sociales, legales y administrativos -incluso los de tipo tributario- a los intercambios de

\footnotetext{
${ }^{11}$ Las reglas de la política económica de las tres décadas de globalización neoliberal tienen su hito fundacional en el denominado Consenso de Washington (1989) alcanzado por el Ejecutivo y el Legislativo estadounidense y el Fondo Monetario Internacional y el Banco Mundial, y apoyado por destacados grupos de presión y sus asesores económicos (GEORGE, 2004; RODRIK, 2012). Las diez medidas que componían este producto político-económico-intelectual se pensaron, inicialmente, para que las deprimidas economías de los países de América Latina empezasen a crecer. En pocos años se convirtieron en un programa mundial o global.

${ }^{12}$ Por ejemplo, la competitividad, las reformas estructurales, la incentivación del espíritu empresarial, las privatizaciones o la extensión del mercado a todos los recursos atractivos para el interés privado lucrativo ( $a d$ $e x$., aguas, suelo, aire, sanidad, educación, dependencia, etc.).
} 
mercancías, a los flujos de capitales y a todos los recursos de interés privado lucrativo (la liberalización del comercio y de las inversiones). Y, cuarta, la anemia estatal mediante bajadas (populistas) de impuestos y de gastos (la disciplina presupuestaria) y políticas legislativas y ejecutivas de mínimos, respetuosas con unas sacrosantas libertad (formal) y propiedad privada, lo que por ejemplo favorece la elección de la normativa aplicable más favorable a los intereses privados que se cobijan bajo esta política y ética neoliberal. Avancemos mínimamente en los resultados de esta ideología y esta política.

Esta combinación de satanización de lo público y lo social y de endiosamiento de lo privado y de la eficiencia de mercado, acontece en un momento de cambio de las relaciones económicas y políticas mundiales. El largo ciclo económico neoliberal (desde la década de los noventa del pasado siglo hasta la Gran Recesión de finales de 2007) coincide con un hecho radicalmente nuevo, que ha agravado exponencialmente sus daños: la globalización de la economía mundial. La interdependencia económica de todos los Estados ha debilitado sobremanera a los Estados nacionales y de facto ha convertido en soberanos a unos mercados neoliberales y neoliberalizados. La globalización económica, pues no se extiende linealmente a otros ámbitos, arremete por diversas vías y no siempre frontales contra el Estado del bienestar y contra su versión más reducida, el Estado social. Los objetivos de las políticas económicas nacionales se centran en la estabilidad de precios. Los instrumentos tradicionales de política económica (v. gr., el déficit público, la política monetaria, la política fiscal o la política de rentas) se reducen, cuando no resultan ineficaces. La capacidad recaudatoria de los Estados resulta mermada, igual que el principio de territorialidad de los tributos y de las mismas normas imperativas. La consecuencia, totalmente previsible, es que las (desacreditadas, por ineficientes) cargas legales, sociales e impositivas generan efectos indeseados, como la huida a los Estados más permisivos de las grandes empresas y de la actividad productiva en general: la tan temida deslocalización de actividades económicas y capitales.

Estas nuevas ideologías y políticas no han generado el crecimiento estable que profetizaban; pero aunque se silencie, si exigen un incremento muy considerable de algunos gastos públicos. Por ejemplo, y enlazamos con los dos procesos de innovación social que nos interesan (las empresas de inserción y las cláusulas sociales en la contratación pública), la expulsión del mercado de trabajo de ciertos colectivos - convertidos en millones de personas con la vigente y muy dilatada Gran Recesión- obliga a los Estados nacionales al pago de 
prestaciones por desempleo, de prestaciones asistenciales y a la intensificación de las políticas activas de empleo (DEFOURNY, FAVREAU y LAVILLA, 1997; MARTÍN PUEBLA, 2007). La afirmación precedente no es una opinión doctrinal, sino la constatación de una realidad dura en lo económico y cruel en lo social y en lo ético.

Así, según las previsiones de la Comisión Europea, ampliamente superadas, el desempleo iba a rebasar en el conjunto de la Unión el 10 por 100 en 2010, con lo que el gasto social pasaría del 27,5 por 100 al 30,8 por 100 del PIB entre 2007 y $2010^{13}$. En la realidad el desempleo ha marcado un nuevo récord en la zona euro en agosto de 2012 (11,4 por 100), y de un 10,5 por 100 en los 27 Estados de la Unión Europea. Y, mucho más cerca, España, con la tasa de paro más elevada de toda la Unión, situó su cifra de desempleo en el 25,1 por 100. Los datos no mejoran con las políticas, cuestionadas incluso por los partidarios del neoliberalismo, de austeridad (la falacia de la austeridad expansiva), y son especialmente dolorosos en el caso del desempleo juvenil: 22,7 por 100 en la Unión Europea, 22,8 por 100 en la eurozona y 52,9 por 100 en España ${ }^{14}$.

La degradación del Estado social español, el hundimiento de los derechos sociales y económicos de sus ciudadanos (incluidas las simples expectativas de promoción o ascenso social), el acrecentamiento de las desigualdades sociales, unido a la aceleración de los procesos de empobrecimiento y exclusión social, son singularmente graves en España (FUNDACIÓ CAIXA CATALUNYA, 2008; FUNDACIÓN FOESSA, 2013) ${ }^{15}$.

La globalización económica, pues no va mucho más allá ${ }^{16}$, y los cambios económicos, organizativos y tecnológicos que la acompañan (lo que también constituye innovación social,

\footnotetext{
${ }^{13}$ Comunicación de la Comisión acerca de la Propuesta de informe conjunto sobre protección social e inclusión social (2010), COM (2010) 25 final, de 5 de febrero de 2010. La documentación citada puede consultarse en www.europa.eu.

${ }^{14}$ Vid Diario El País (La UE advierte de que el alto paro puede causar un "desastre económico y social”), de 1 de octubre de 2012.

${ }^{15}$ Bajo el título "Más desigualdad”, y el subtítulo de "El aumento de la pobreza en España tras la persistente crisis puede hipotecar el futuro”, el Diario El País dedicaba su editorial (el del 1 de abril de 2013) a este último informe, y concluía con la advertencia de que las sociedades más desiguales son las que tienen mayores dificultades para crecer.

${ }^{16}$ Salvo que se intenten patrimonializar a favor de la causa de la globalización económica los avances científicos y tecnológicos en las materias de comunicación, informática y nuevas tecnologías. Estos avances estarían con nosotros aunque no se hubiesen liberalizado (tanto) los mercados y los flujos de capitales, y se aplicasen -como era tónica general- medidas proteccionistas selectivas y límites y controles a los intercambios comerciales y financieros, incluidos los tipos de cambio. Así hace, con acierto para sus intereses y grave daño para el resto del mundo, alguna de las nuevas potencias económicas mundiales (v. gr., China) (RODRIK, 2012).
} 
pero no precisamente orientada al desarrollo personal y social), han beneficiado a una minoría de ciudadanos ricos de los países ricos (y también de economías emergentes) y ha generado un reparto de la riqueza muy desigual en el primer mundo, con el surgimiento del aludido cuarto mundo: las personas y los colectivos excluidos, cuando no directamente marginados, en los países desarrollados. A la globalización económica neoliberal podríamos aplicarle el siguiente eslogan: concentra la riqueza, y socializa y cronifica la pobreza. Y lo más grave, aunque excede de nuestro objetivo, es que la diseñada globalización neoliberal en lugar de aportar un crecimiento estable, como prometía, está sumiendo a los países empobrecidos en la pobreza extrema y en la fractura política, institucional y social ${ }^{17}$. El proceso continúa, los mercados no van a pensar en los excluidos, pues quienes los controlan -las élites económicas conectadas a las políticas- tienen unos objetivos y, especialmente, unos intereses muy distintos (CALVO BERNARDINO y PAÚL GUTIÉRREZ, 2000; HESSEL, 2011; AA. VV., 2011; NAVARRO, TORRES LÓPEZ y GARZÓN ESPINA, 2011; RODRIK, 2012; SANDEL, 2013). Aunque nos duele advertirlo estamos asistiendo, impasibles, a acentuados procesos mundiales y nacionales de darwinismo social.

\section{LAS EMPRESAS DE INSERCIÓN SOCIOLABORAL: DE LA INNOVACIÓN SOCIAL ENDÓGENA A SU INSTITUCIONALIZACIÓN}

\section{A) Las empresas de inserción como agentes de la nueva economía social}

En España y en buena parte de los Estados de la Unión Europea (v. gr., Francia, Italia, Alemania o Reino Unido), desde mediados de los ochenta del pasado siglo son numerosas las iniciativas privadas y públicas y, dentro de éstas últimas, comunitarias, estatales, autonómicas $\mathrm{y}$, especialmente, locales, que han involucrado a las empresas de la economía social en el diseño y, sobre todo, en la ejecución de las -nuevas, pues surgen en este momento históricopolíticas activas de empleo (QUINTAO, 2007; CHAVES y MONZÓN, 2007). Entre estas nuevas empresas sociales o solidarias asumen una creciente importancia las empresas de inserción y sus entidades (no lucrativas) promotoras. Estos nuevos empresarios adicionan, a su actividad estrictamente empresarial, la finalidad esencial de integración laboral y social de personas pertenecientes a colectivos en situación o riesgo de exclusión social (ÁLVAREZ

\footnotetext{
${ }^{17}$ Vid las políticas y complacientes afirmaciones de Ban Ki-moon (Secretario general de las Naciones Unidas), en "Mil días para cumplir la promesa del Milenio", Diario El País, de 4 de abril de 2013, p. 27. Con referencia a los países más pobres y vulnerables, donde residen 1.500 millones de personas, afirma que "Muchos de ellos no han alcanzado ni siquiera uno de los Objetivos de Desarrollo del Milenio".
} 
VEGA, 1999; LÓPEZ-ARANGUREN, 2000; GARCÍA MAYNAR, 2007; PANIAGUA ZURERA, 2008; MELIÁN, CAMPOS y SANCHIS, 2011).

En nuestra experiencia las empresas de inserción surgen a impulsos de entidades no lucrativas -asociaciones y fundaciones- especializadas o dedicadas a la asistencia y la inclusión social. Los estudios de campo realizados en España constatan que fueron dos los promotores más frecuentes de estos empresarios de la nueva económica social: la Iglesia católica a través de Cáritas y las asociaciones vecinales o ciudadanas (p. ej., el movimiento Emaús, que en 1980 constituyó el grupo Emaús Fundación Social, Cruz Roja Española o la Red de Apoyo a la Inserción Social y Laboral, RAIS). A raíz de su fomento público, principalmente por las Administraciones locales y autonómicas, estas entidades dieron vida a un nuevo instrumento (de innovación social para el desarrollo, no lo olvidemos) al servicio de las políticas activas de empleo. Estas primeras promotoras de las iniciativas de inclusión social toman conciencia de que la inserción sociolaboral demanda unas prácticas de trabajo reales, siquiera en un contexto empresarial y en un mercado de trabajo más tutelado. Los pasos siguientes fueron dos: primero, el ejercicio de una actividad económica en forma empresarial para el mercado mediante la creación de una empresa controlada y orientada en sentido social; y, segundo, el establecimiento de relaciones con los sectores público y privado con un doble objetivo a su vez, de un lado, la oferta a estos sectores de los bienes y servicios producidos por estas empresas y, por otro, la obtención de oportunidades de empleo para sus trabajadores de inserción, una vez que éstos han adquiridos hábitos sociales y laborales normalizados fruto de itinerarios o procesos personalizados de inserción sociolaboral.

En la doctrina económica y jurídica no existe acuerdo acerca de la ubicación conceptual y sistémica de las empresas de inserción sociolaboral (CHAVES y MONZÓN, 2007 y 2008). A nuestro entender estas empresas y empresarios constituyen un subsector de la economía social, denominado la nueva economía social o la economía solidaria (PANIAGUA ZURERA, 2011-a). Sus manifestaciones son tradicionales empresarios de la economía social (como asociaciones y fundaciones), a los que se unen nuevas formulas organizativas $^{18}$ (innovaciones sociales para el desarrollo, en suma) como las empresas de inserción y sus entidades promotoras o las cooperativas no lucrativas de iniciativa social. Para

\footnotetext{
${ }^{18}$ Que generan hibridaciones causales en nuestro sistema jurídico, con nuevos empresarios que tienen cuerpo (forma) de sociedad y alma (fin) de asociación. Lo que obliga a repensar la dogmática de nuestro Derecho de sociedades y del de asociaciones (PANIAGUA ZURERA, 2011-a).
} 
estos empresarios lo esencial es su fin o misión, junto a la satisfacción de los valores y los principios de la economía social, mediante el ejercicio empresarial de una actividad económica dirigida al mercado, pues la obtención de beneficios o es inexistente o está muy limitada. Los recursos de estas empresas proceden del mercado (los ingresos por los bienes y servicios ofertados), y también de fuentes ajenas al mercado (p. ej., la promoción pública, las ayudas privadas y el voluntariado social).

No faltan aproximaciones a las empresas de inserción que las ubican entre las entidades no lucrativas, esto es, la teorización anglosajona de las non profit (GIMÉNEZ MARÍN, 2010) ${ }^{19}$. No compartimos esta perspectiva que, siquiera en forma bienintencionada, priva a la economía social de su identidad (los valores y los principios de la economía social) y de su horizonte o misión (la constitución de poderes compensadores en los mercados). O, en otros términos, conduce a una nueva -pues no sería la primera- instrumentalización capitalista de la economía social (PANIAGUA ZURERA, 2011-a). Es interesante advertir que nuestra legislación estatal y autonómica normalmente emplea los términos de economía social -y no los de empresarios sociales- para referirse a las empresas de inserción, como veremos.

La noción de empresa social acuñada por la Comisión Europea sí está más próxima a los valores, a los principios y al proyecto, misión o causa de las empresas de la economía social. En la citada Propuesta de Reglamento sobre un Programa para el Cambio y la Innovación Sociales aporta, a los efectos de esta norma, la definición que sigue de empresa social: "una empresa cuyo principal objetivo consista en lograr un impacto social más que en generar beneficios para los propietarios y agentes interesados; que actúe en el mercado por medio de la producción de bienes y servicios con espíritu emprendedor e innovador, y utiliza los excedentes principalmente para alcanzar objetivos sociales; y que sea objeto de una gestión responsable y transparente, en especial mediante la participación de los trabajadores, los clientes y los agentes interesados afectados por su actividad”.

La nueva economía social está vivificando, conviene enfatizarlo, el proyecto y la utopía originaria de la cooperación y de la economía social: por un lado, su carácter

\footnotetext{
${ }^{19}$ En una línea argumental y estratégica similar, el CESE (vid los citados dictámenes) propone sustituir la categoría conceptual de la economía social y sus agentes, por la idea de la "empresa social", y cuando detalla las características de estas empresas sociales advertimos que están más cerca de las non profit organizations que de las empresas y empresarios de la economía social.
}

REVESCO No 112 - Extraordinario en Homenaje al Profesor Alfonso Carlos MORALES

GUTIÉRREZ - ISSN: 1885-8031 - www.ucm.es/info/revesco 
alternativo a la empresa capitalista tradicional y, por otro, su función sistémica de pugna política, ideológica, cultural y ética con los valores de unas economías de mercado que han acentuado su faz liberal (rectius: neoliberal) en claro detrimento de su rostro social (la debilitada economía social de mercado y el disminuido Estado social). Frente a fenómenos de isomorfismo organizativo y empresarial de agentes tradicionales de la economía social (v. gr., algunas sociedades cooperativas y laborales que de facto operan en el mercado como titulares de empresas capitalistas para, alegan, competir mejor en los nuevos escenarios globales), las empresas y empresarios de la nueva economía social conservan su ideario -y su función institucional y sistémica- de poderes compensadores en los mercados orientados a la apertura y el enriquecimiento del sistema económico capitalista con objetivos como su democratización y humanización, la preservación y el fomento del pluralismo empresarial, la mejora de la competencia económica y el incremento de los contenidos sociales y éticos en el ejercicio de la libertad de empresa (PANIAGUA ZURERA, 2011-a).

\section{B) La integración sociolaboral de personas en situación o riesgo de exclusión}

\section{social mediante la promoción de empresas de inserción}

Después de algunas limitadas tentativas por parte de la legislación laboral estatal ${ }^{20}$, el régimen sustantivo de las empresas de inserción (EI, en abreviaturas) está contenido en la Ley estatal 44/2007, de 13 de diciembre (LEI, en siglas), que nuestras Autonomías -como ya hicieran algunas ${ }^{21}$ - han de tomar como punto de partida para el ejercicio de sus competencias normativas sobre asistencia social y de ejecución de la legislación laboral.

La LEI estaba pendiente de un extenso recurso de inconstitucionalidad promovido por el Gobierno valenciano (el n $\mathrm{n}^{\mathrm{0}}$ 2136-2008, admitido a trámite el 15 de abril de 2008, contra los artículos $1.1 ; 2.1 ; 3 ; 4 ; 5 ; 6 ; 7 ; 8 ; 9.3 ; 10$; la D. A. $5^{\text {a }}$, las DD. TT. $1^{\text {a }}, 2^{\text {a }}$ y $3^{\text {a }}$; y la D. F. $\left.5^{\text {a }}\right)$. La

\footnotetext{
${ }^{20}$ En Derecho estatal, la Ley 12/2001, de 9 de julio, de medida urgentes de reforma del mercado de trabajo para el incremento y la mejora de su calidad (v. sus arts. 4.1.3, 6.4 y D. A. 9a); y, la Ley 43/2006, de 29 de diciembre, de mejora del crecimiento y del empleo (v. sus arts. 1.2, 2.5, D. A. $2^{\mathrm{a}}$ y D. F. $5^{\mathrm{a}}$ ) (PANIAGUA ZURERA, 2008). La citada D. A. $9^{\mathrm{a}}$ Ley 12/2001 puso nombre a estas empresas: "de promoción e inserción laboral de personas en situación de exclusión social". Y enunció sus rasgos característicos: $1^{\circ}$ ) Pueden adoptar cualquier "forma jurídica"; $2^{\circ}$ ) Pueden dedicarse a cualquier "actividad económica"; $3^{\circ}$ ) Deben dedicar "habitualmente no menos del 30 por 100 de sus puestos de trabajo al empleo" de personas en situación de exclusión social; $4^{\circ}$ ) Deben "formarles y adiestrarles en el ejercicio normalizado de una actividad laboral"; $5^{\circ}$ ) Tendrán "como fin primordial de su objeto social la plena integración laboral y el acceso al empleo ordinario" de estas personas; y $6^{\circ}$ ) Podrán "inscribirse voluntariamente en el registro público que a tal efecto se determine reglamentariamente".

${ }^{21}$ Por ejemplo, el Decreto andaluz 193/2010, de 20 de abril, que regula la calificación y crea el Registro de empresas de inserción en Andalucía.
} 
sentencia del Tribunal Constitucional (Pleno) 288/2012, de 29 de noviembre, ha desestimado la práctica totalidad del recurso. Su fallo declara inconstitucionales las DD. TT. $1^{\text {a }} .2$ y $3^{\text {a }}$ y fija la interpretación conforme a la Constitución del art. 10 LEI. En todo lo demás da la razón al Estado pues argumenta, lo que es muy discutible, que todo el régimen de las EI es competencia estatal por constituir "legislación laboral" (art. 149.1.7 $\left.7^{\mathrm{a}} \mathrm{CE}\right)^{22}$. En consecuencia, nuestra Autonomías deben cumplir la D. T. $1^{\text {a }} .1$ LEI, que tiene este mandato: "Las empresas de inserción ya existentes a la fecha de entrada en vigor de la Ley, para acogerse a lo regulado en la misma, deberán adaptarse a sus previsiones en un plazo de un año a partir de dicha entrada en vigor", sin que resulte posible -pues el Tribunal Constitucional lo ha rechazado- que las Autonomías adapten la normativa exclusiva estatal como preveía la D. T. 1 ${ }^{\text {a }} 2$ LEI [Fundamento jurídico 6 letra j) STC 228/2012] ${ }^{23}$.

La lectura de la Exposición de motivos LEI patentiza una doble conexión de las EI como (sic) "nuevas formas de organización": la teorización y la práctica de las instituciones propias de un Estado democrático y, en especial, de un Estado social (v. Preámbulo y arts. 1.1 y 9.2 CE); y, las empresas y empresarios de la economía social (v. arts. 35, 38, 40 y 129.2 CE). Esta Exposición se refiere a las empresas de inserción como "una tipología especial dentro de las empresas de carácter social”.

La empresa de inserción que define la ley, a decir de su Exposición de motivos, "es aquella sociedad mercantil, incluidas por tanto las sociedades laborales, o sociedad cooperativa que, debidamente calificada, realice cualquier actividad económica de producción de bienes o prestación de servicios, teniendo como fin primordial de su objeto social la integración y formación sociolaboral de personas en situación de exclusión social".

El art. 4 LEI, bajo el título “Concepto de empresa de inserción”, diseña la noción legal apoyada en estos cuatro elementos: $1^{\circ}$ ) La EI debe adoptar alguna de las formas jurídicas previstas por el legislador estatal ("sociedad mercantil o sociedad cooperativa legalmente constituida”). $2^{\circ}$ ) Debe estar “debidamente calificada" por los servicios autonómicos correspondientes a su centro de trabajo. $3^{\circ}$ ) Debe realizar una actividad económica que "tenga

\footnotetext{
${ }^{22}$ En otra sede habrá que analizar detenidamente este fallo, que compartimos en su resultado final; pero, no así en su fundamentación jurídica, lo que no es poco para la ciencia del Derecho.

${ }^{23}$ Sobre este extraño mandato de adaptación normativa el Alto Tribunal afirma: "no es conforme con el reparto constitucional de competencias, pues en éste se atribuye al Estado la legislación laboral en su integridad, no siendo posible que el Estado haga dejación de esta atribución remitiendo su ejercicio a las Comunidades Autónomas porque, como hemos declarado reiteradamente, las competencias tienen carácter irrenunciable".
} 
como fin" la integración y la formación sociolaboral de personas en situación de exclusión. Y, $4^{\circ}$ ) "Deberá proporcionar" a estos trabajadores unos procesos o "itinerarios de inserción" sociolaboral (PANIAGUA ZURERA, 2008; VALLECILLO GÁMEZ y MOLINA NAVARRETE, 2008; AGUILERA IZQUIERDO, 2009).

Nos interesa centrarnos en los dos últimos requisitos de la conceptuación legal (y de la innovación social para el desarrollo institucionalizada) de las EI: primero, el fin social y de interés general que es el alma de la EI, como veremos; y, segundo, el medio para dar plenitud a este fin, causa o misión en sentido amplio y no técnico-jurídico, constituido por la obligación legal que pesa sobre las EI de proporcionar a sus beneficiarios unos procesos personalizados y asistidos de trabajo remunerado, formación en el puesto de trabajo y habituación laboral y social (art. 4 párr. segundo LEI).

\section{C) El fin que deben perseguir las empresas de inserción}

La EI, con independencia de la forma jurídica utilizada para su personificación ("sociedad mercantil o sociedad cooperativa legalmente constituida” y, en forma transitoria, asociación o fundación) (v. art. 4 párr. primero y D. T. $2^{\mathrm{a}}$ LEI), tiene per se un fin inmanente y primordial a la institución de empresa de inserción. El legislador se ha encargado de indicarnos, con reiteración, cuál es su fin social y de interés general. La aludida Exposición de motivos LEI afirma que el objetivo de las EI es "servir como un instrumento más a la inserción de los sectores excluidos de la sociedad, articulándose en este caso tal inserción a través de una prestación laboral en la empresa de inserción que permita la transición de la persona en situación de exclusión social al empleo ordinario”.

El articulado de la LEI mantiene la misma claridad, y mayor insistencia aún, en la identificación de la finalidad social y de interés general de los tipos sociales calificados como EI. Estamos ante empresarios sociales (desarrollan "cualquier actividad económica de producción de bienes y servicios") cuyo "objeto social" debe tener "como fin la integración y formación sociolaboral de personas en situación de exclusión social como tránsito al empleo ordinario" (art. 4 párr. primero) ${ }^{24}$. El legislador concreta este fin específico con dos exigencias que se traducen en sendas obligaciones legales. Por un lado, las EI deben tener y

\footnotetext{
${ }^{24}$ La integración en el mercado laboral ordinario como objetivo final de la EI está presente en toda la LEI. V., además de los elementos normativos glosados en el texto, los arts. 1, 3 párr. primero, 5 letra f), 10.2 letra c), 10.3 letras a) y c), la D. A. $3^{\mathrm{a}}$ y la D. A. $4^{\mathrm{a}}$.
} 
aplicar, a los trabajadores en proceso de inserción, unos itinerarios de inserción sociolaboral (v. infra). Por otro, las EI “deberán tener servicios de intervención o acompañamiento para la inserción sociolaboral que faciliten su posterior incorporación al mercado de trabajo ordinario” (art. 4 párr. segundo). En la misma línea teleológica, aunque en sede de fomento público, el trato de favor que prevé la LEI se justifica, y tiene por objetivo, que la EI "pueda cumplir su función social de facilitar la inserción de las personas en situación de exclusión en el mercado de trabajo ordinario" (art. 16.1).

La centralidad del objetivo de integración sociolaboral de los trabajadores en procesos de inserción en el mercado de trabajo ordinario está presente en todo el diseño de la EI y en toda la LEI. La mayoría de los requisitos legales impuestos a las EI están directamente relacionados con este fin social y de interés general, destacando los que siguen: la constitución y participación por una entidad promotora pública o privada no lucrativa; el destino de, al menos, el 80 por 100 de los resultados o beneficios disponibles del ejercicio económico a la mejora o ampliación de sus estructuras productivas o de inserción; o tener los medios necesarios para cumplir las obligaciones derivadas de los itinerarios de inserción sociolaboral (arts. 5 y 6 LEI). De ahí que la primera causa legal de descalificación administrativa como EI sea (sic) "Incumplir el fin definido en el artículo 4 de esta Ley" (art. 8.1 letra a). Y que la primera infracción administrativa muy grave tipificada para las EI sea, "Desarrollar las actividades sin cumplir el fin primordial de las empresas de inserción de integración sociolaboral de las personas en situación de exclusión social” (v. D. F. $1^{\mathrm{a}}$ LEI).

En forma muy discutible la LEI ha optado por la regulación de las EI de transición $^{25}$ (LÓPEZ-ARANGUREN, 2002; CH. MARCUELLO, 2007), esto es, las que dedican parte de sus puestos de trabajo a personas en proceso de inserción ${ }^{26}$, que de esta forma adquieren o completan su formación sociolaboral en un contexto empresarial y, pasado un tiempo, el objetivo es su inserción en el mercado de trabajo ordinario ${ }^{27}$. Precisamente la LEI demanda

\footnotetext{
${ }^{25}$ En nuestra experiencia también existen las EI finalistas que ofertan de forma permanente puestos de trabajo a personal de inserción sociolaboral. Estas EI finalistas han quedado fuera, sin justificación razonable, de la LEI; pero, nada impide su constitución y funcionamiento. Lo más correcto hubiese sido la regulación de estas $E I$ finalistas y, en su caso, la modulación de su régimen de fomento o promoción pública.

${ }^{26}$ Desde su calificación administrativa como EI deben mantener, en cómputo anual, un porcentaje de trabajadores en proceso de inserción de al menos el 30 por 100 del total de la plantilla durante los primeros tres años de su actividad y, como mínimo, del 50 por 100 a partir del cuarto año, no pudiendo ser el número de los citados trabajadores inferior a dos [art. 5 letra c), Requisitos].

${ }^{27}$ La EI tendrá como "fin la integración y formación sociolaboral de personas en situación de exclusión social como tránsito al empleo ordinario" (art. 4 párr. primero in fine).
} 
que los contratos de trabajo entre la EI y los trabajadores en situación o riesgo de exclusión social deben "celebrarse por duración determinada, ajustándose a las modalidades de contratación previstas en la legislación laboral" (art. 12.1) ${ }^{28}$. El aludido contrato también puede celebrarse bajo la modalidad -y es la novedad que aporta o recupera la LEI- de contrato temporal de fomento del empleo (arts. 12.1 y 15), que "podrá concertarse por un periodo mínimo de doce meses y máximo de tres años" (art. 15.4) ${ }^{29}$.

El carácter de innovación social para el desarrollo de la EI resulta nítido cuando nos detenemos en las personas en situaciones o riesgos de exclusiones sociales, desempleadas e inscritas en los servicios públicos de empleo que pueden ser contratadas, como trabajadores en proceso de inserción, por las EI. Según la LEI (art. 2.1), los colectivos incluidos, tras las sugerencias del Consejo Económico y Social y las enmiendas admitidas durante el trámite parlamentario (CES, 2007), son (sic):

“a) Perceptores de Rentas Mínimas de Inserción, o cualquier otra prestación de igual o similar naturaleza, según la denominación adoptada en cada Comunidad Autónoma, así como los miembros de la unidad de convivencia beneficiarios de ellas.

b) Personas que no puedan acceder a las prestaciones a las que se hace referencia en el párrafo anterior, por alguna de las siguientes causas:

$\left.1^{o}\right)$ Falta del periodo exigido de residencia o empadronamiento, o para la constitución de la Unidad Perceptora.

$\left.2^{\circ}\right)$ Haber agotado el periodo máximo de percepción legalmente establecido.

c) Jóvenes mayores de dieciocho años y menores de treinta, procedentes de Instituciones de Protección de Menores.

d) Personas con problemas de drogodependencia u otros trastornos adictivos que se encuentren en proceso de rehabilitación o reinserción social.

\footnotetext{
${ }^{28}$ Tras varios intentos en el Congreso de los Diputados, la exigencia de que la contratación debe ser de carácter temporal se introdujo durante la tramitación en el Senado.

${ }^{29}$ La LEI admite que esta modalidad pueda celebrarse "por una duración menor si, dentro del itinerario de inserción previamente pactado, así se aconseja por los Servicios Sociales Públicos competentes para el seguimiento del proceso de inserción, sin que en ningún caso dicha duración pueda ser inferior a seis meses" (art. 15.4 párr. primero).
}

\footnotetext{
REVESCO No 112 - Extraordinario en Homenaje al Profesor Alfonso Carlos MORALES

GUTIÉRREZ - ISSN: 1885-8031 - www.ucm.es/info/revesco
} 
e) Internos de centros penitenciarios cuya situación penitenciaria les permita acceder a un empleo y cuya relación laboral no esté incluida en el ámbito de aplicación de la relación laboral especial regulada en el artículo 1 del Real Decreto 782/2001, de 6 de julio, así como liberados condicionales y ex reclusos.

f) Menores internos incluidos en el ámbito de aplicación de la Ley Orgánica 5/2000, de 12 de enero, reguladora de la responsabilidad penal de los menores, cuya situación les permita acceder a un empleo y cuya relación laboral no esté incluida en el ámbito de aplicación de la relación laboral especial a que se refiere el artículo 53.4 del Reglamento de la citada Ley, aprobado por el Real Decreto 1774/2004, de 30 de julio, así como los que se encuentran en situación de libertad vigilada y los ex internos.

g) Personas procedentes de centros de alojamiento alternativo autorizados por las Comunidades Autónomas y las ciudades de Ceuta y Melilla.

h) Personas procedentes de servicios de prevención e inserción social autorizados por las Comunidades Autónomas y las ciudades de Ceuta y Melilla”.

La legislación autonómica sobre fomento y control de las EI nos presenta a otros colectivos de personas que pueden ser contratadas por estas empresas, junto a una enumeración abierta a otras situaciones de exclusión sociolaboral. Entre estos colectivos figuran los jóvenes en riesgo de exclusión, las minorías étnicas, las mujeres con diversa problemática, los parados de larga duración, especialmente, los mayores de 48 años, o los inmigrantes (GARCÍA MAYNAR, 2007). Estas personas encuentran cobertura para su contratación por las EI en las amplias y frecuentes remisiones de la LEI a las competencias normativas y ejecutivas autonómicas en materia de asistencia y servicios sociales (v. arts. 2, 7, 9,10 , D. A. $3^{\mathrm{a}}$ y D. F. $2^{\mathrm{a}}$ ).

Debemos destacar, finalmente, que las EI actúan en el escenario de los excluidos por causas sociales, no por minusvalías físicas o psíquicas que tienen otra problemática y otros 
instrumentos (v. gr., asistencia sanitaria y educativa, subsidios, deducciones fiscales, cobertura de prestaciones sociales, y medidas ad hoc en materia de integración laboral) ${ }^{30}$.

\section{D) Los itinerarios de inserción sociolaboral}

La principal consecuencia del fin social y de interés general específico de los tipos sociales titulares de EI es que "deberán proporcionar" a los trabajadores incluidos en los colectivos de personas en situación o riesgo de exclusión que recogen la LEI y la normativa autonómica sobre fomento y control de las EI, “como parte de sus itinerarios de inserción”, "procesos personalizados y asistidos de trabajo remunerado, formación en el puesto de trabajo, habituación laboral y social” (art. 4 párr. segundo). Estos itinerarios de inserción son el instrumento para que las EI puedan "resolver problemáticas específicas derivadas de la situación de exclusión” (art. 3.2) y hacen posible el tránsito del trabajo en proceso de inserción, desarrollado en la EI, al mercado de trabajo ordinario.

La Ley 56/2003, de 16 de diciembre, de Empleo (LE, en siglas), regula en términos generales los itinerarios de inserción laboral en el capítulo dedicado a las políticas activas de empleo (arts. 23 a 26 LE, en la redacción dada por el Real Decreto-Ley 3/2011, de 18 de febrero). El diseño y la ejecución de estas políticas estarán presididas, como primer principio, por el "tratamiento individualizado y especializado" de las personas desempleadas [art. 24.1 letra a) LE]. Y, entre las medidas generales que integran estas políticas figuran la generación de oportunidades para colectivos con especiales dificultades, que se describen en estos términos: "acciones y medidas de inserción laboral de colectivos que, de forma estructural o coyuntural, presentan dificultades para el acceso y la permanencia en el empleo" [art. 25.1 letra f) LE]. Además, es muy relevante que en la definición general de las políticas activas de empleo figura, expresamente, "el fomento del espíritu empresarial y de la economía social" (art. 23.1 LE), mientras en las aludidas medidas figuran la promoción de iniciativas empresariales mediante “el trabajo autónomo y la economía social” [art. 25.1 letra g) LE].

Si volvemos a la LEI, el legislador concreta que en la programación y ejecución de los itinerarios de inserción sociolaboral estarán presentes, junto a las EI y los servicios públicos

\footnotetext{
${ }^{30}$ Vid, en Derecho estatal, el art. 49 CE, la reformada Ley 13/1982, de 7 de abril, de integración social de minusválidos, el también modificado Real Decreto 1451/1983, de 11 de mayo, que regula el empleo selectivo y las medidas de fomento del empleo de trabajadores minusválidos, y el Real Decreto 2273/1985, de 4 de diciembre, que regula los centros especiales de empleo de minusválidos.
} 
sociales y de empleo competentes ${ }^{31}$, las entidades promotoras de las EI. La legislación autonómica sobre fomento y control de estas empresas ha desarrollado la participación de las entidades promotoras en los itinerarios de inserción. En abierto contraste, la LEI es muy parca en el desarrollo de esta idea, que no aparece en los preceptos dedicados específicamente a las entidades promotoras [v. arts. 5 letra a) y 6]. No obstante, hemos de entender implícita esta posible participación de la entidad promotora en los itinerarios de inserción, pues la LEI exige que su "objeto social”,32 “contemple la inserción social de personas especialmente desfavorecidas" (art. 6). El legislador estatal confirma esta exégesis cuando prevé que las entidades promotoras "que realicen servicios de acompañamiento para la inserción sociolaboral", pueden recibir ayudas de las Administraciones públicas "para la ejecución de los mismos" (art. 16.5).

\section{LAS ClÁUSUlaS SOCIALES EN LA CONTRATACIÓN PÚBLICA: DE SU REIVINDICACIÓN SOCIAL A SU RECONOCIMIENTO LEGAL Y JURISPRUDENCIAL}

\section{A) Las medidas de promoción pública en la LEI: una tarea inacabada}

El trato de favor que prevé la LEI se justifica, y tiene por objetivo, que la EI "pueda cumplir su función social de facilitar la inserción de las personas en situación de exclusión en el mercado de trabajo ordinario" (art. 16.1). Pero, la lectura de la Exposición de motivos y del articulado de la LEI dedicado a estas medidas de fomento público, dejan en el jurista una sensación de vacío y postergación, pues las iniciativas reivindicadas por el sector o se omiten, o se remiten a futuras actuaciones normativas y administrativas no concretadas ni comprometidas. Por ejemplo el legislador estatal reconoce, y así lo confirman los estudios existentes (VECIANA, 2007), la existencia de unos sobrecostes para la EI derivados de la contratación del personal de acompañamiento que necesitan las personas en proceso de inserción, de las mayores tasas de absentismo laboral -al menos, al principio del itinerario de inserción- de los trabajadores de inserción, y de la menor productividad laboral de los trabajadores de inserción que se incorporan a los citados itinerarios. Sin embargo, la LEI no

\footnotetext{
${ }^{31}$ A los que habría que unir, como posibilidad que es verificada por la práctica de nuestras EI, la colaboración de las asociaciones de las empresas de inserción que, como dispone la LEI, pueden organizar "servicios de asesoramiento, formación, asistencia jurídica o técnica y cuantos sean convenientes a los intereses de su socios" (art. 16.6).

${ }^{32}$ Expresión que no es adecuada a la forma jurídica no lucrativa que debe adoptar la entidad promotora (v. art. $6)$.
}

REVESCO No 112 - Extraordinario en Homenaje al Profesor Alfonso Carlos MORALES

GUTIÉRREZ - ISSN: 1885-8031 - www.ucm.es/info/revesco 
establece ninguna nueva medida de aplicación directa para compensarlos, salvo el mantenimiento de unas volátiles o mutables bonificaciones en las cuotas a la Seguridad Social (v. art.17.3).

Las medidas de fomento más esperadas y demandas por el sector de las EI, o no se contienen, o no se concretan, en la LEI. Por un lado, se silencia toda referencia a un régimen fiscal favorable para el empresario de inserción coherente con su función social y de interés general, pese a que la demanda irrumpió tímidamente durante la tramitación del proyecto de ley en el Senado. Por otro, las cláusulas o los criterios sociales a favor de los empresarios de inserción en la contratación con las Administraciones públicas (las "cláusulas sociales”) y la reserva de cuotas de mercado para estos empresarios (los "mercados tutelados") (LEMES ZABALEGUI, 2006; RUIZ, RETOLAZA y MUGARRA, 2007; REAS Euskadi, 2010) sólo aparecen, y referidos a las cláusulas sociales, en forma muy tímida en la D. A. $1^{\text {a }}$ LEI. Esta norma admite como simple posibilidad ("podrán incluir"), y no como un mandato legal exigible, las cláusulas sociales ("incluir consideraciones relativas a la situación de exclusión social de los trabajadores vinculados a la realización del contrato”) en la fase de ejecución de la contratación pública (las “condiciones especiales de ejecución de los contratos”) ${ }^{33}$. Este timidísimo mandato está, como veremos, muy lejos de las posibilidades admitidas en el momento de la promulgación de la LEI, tanto por la normativa y la jurisprudencia comunitaria, como por la legislación básica estatal sobre contratos del sector público.

\section{B) La necesidad de las cláusulas sociales en la contratación pública para las} empresas de inserción

La promoción de estas cláusulas sociales dirige su mirada al sector público, a los contratos con las Administraciones públicas y sus entidades dependientes en su calidad de demandantes de bienes y servicios, a las que las EI prestarían obras, servicios y suministros. La idea de fondo es que la contratación pública atienda, valore, y dé contenido y prioridad, en los términos previstos por el legislador competente, a la función social y de interés general desarrollada por el empresario de inserción. De esta forma las Administraciones públicas y el sector público, además de asignar con eficiencia económica sus recursos, los están

\footnotetext{
${ }^{33}$ La citada D. A. $1^{a}$ LEI, bajo el título "Aplicación de la normativa de la Ley de Contratos del Sector Público", dispone: "Las condiciones especiales de ejecución de los contratos podrán incluir consideraciones relativas a la situación de exclusión social de los trabajadores vinculados a la realización del contrato de conformidad con lo dispuesto en la legislación de contratos del sector público".
} 
rentabilizando socialmente, pues adquieren bienes o servicios en condiciones de mercado y contribuyen a lograr objetivos de política social, en este caso, de las políticas de asistencia e integración social y de las políticas activas de empleo hacia los más desfavorecidos. Pensemos, asimismo, en los ingresos públicos $-\mathrm{y}$, en el ahorro de gasto público- derivados de la actividad económica de las EI (p. ej., por el pago de impuestos y de cotizaciones sociales, por el abono de salarios y la remuneración de los demás recursos productivos, y por el ahorro de prestaciones sociales públicas). Por su parte, las EI obtienen, de un lado, mercado para el ejercicio empresarial de su actividad económica y, de otro, oportunidades laborales para personas en situación o riesgo de exclusión social, lo que hace posible el cumplimiento de su fin social y de interés general.

Las cláusulas sociales suponen la inclusión de criterios de este carácter en los procesos de contratación del sector público. Como orienta la práctica y la normativa existente estas cláusulas o criterios sociales pueden diseñarse en los pliegos de condiciones de los contratos del sector público con muy distinto alcance. A saber: $1^{\circ}$ ) Como requisitos previos, esto es, como criterios de admisión o selección en la contratación pública, lo que resulta sumamente difícil fuera del supuesto de los contratos reservados para personas discapacitadas ${ }^{34} .2^{\circ}$ ) Como elementos de adjudicación del contrato público a una empresa, por ejemplo, como criterios de puntuación o valoración o de desempate o preferencia, que hoy no plantean -o no deberían suscitar- problemas de licitud en Derecho comunitario y en Derecho español, aunque sí los originaron en el pasado (v. infra). Y, $3^{\circ}$ ) Como condiciones sociales impuestas a la empresa adjudicataria en la ejecución del contrato público (v. gr., la exigencia de que esta empresa subcontrate con una EI o contrate a personas en situación de exclusión social), estos

\footnotetext{
${ }^{34}$ No analizamos el caso particular constituido por el mercado tutelado o reservado, donde el carácter tan restrictivo de la cláusula social demanda, de hecho, que sólo puedan participar en algunas licitaciones de la contratación pública un determinado tipo de empresas. La vigente Directiva 2004/18/CE del Parlamento Europeo y del Consejo, de 31 de marzo, sobre coordinación de los procedimientos de adjudicación de los contratos públicos de obras, de suministro y de servicios, admite estas reservas para los programas de talleres y empleos protegidos de personas con discapacidad, exigiendo que (sic) "la mayoría de los trabajadores afectados sean personas discapacitadas que, debido a la índole o a la gravedad de sus deficiencias, no puedan ejercer una actividad profesional en condiciones normales" (v. su Considerando 28 y su art. 19).

En nuestro Derecho está directiva está transpuesta en el vigente Real Decreto Legislativo 3/2011, de 14 de noviembre, que aprueba el texto refundido -el segundo- de la Ley de Contratos del Sector Público (TRLCSP). $\mathrm{Su}$ D. A. $5^{\mathrm{a}}$ (Contratos reservados) dispone: "Podrá reservarse la participación en los procedimientos de adjudicación de contratos a Centros Especiales de Empleo, o reservar su ejecución en el marco de programas de empleo protegido, cuando al menos el 70 por 100 de los trabajadores afectados sean personas con discapacidad que, debido a la índole o a la gravedad de sus deficiencias, no puedan ejercer una actividad profesional en condiciones normales. En el anuncio de licitación deberá hacerse referencia a la presente disposición". Adviértase que la Directiva 2004/18/CE exige que la mayoría de los trabajadores sean discapacitados, mientras el TRLCSP lo ha elevado a un mínimo del 70 por 100.
} 
criterios sociales no han planteado problemas para su admisión. Un último avance (rectius: una propuesta por ahora) son los modelos integrales, que combinarían al menos dos de las posibilidades indicadas.

El sector de las EI, con su federación al frente (FAEDEI) ${ }^{35}$, defiende con vehemencia la necesidad de las cláusulas sociales en la contratación pública, pues una de las principales dificultades para las EI es la inexistencia de mercados sociales (ROJO TORRECILLA, 19992000; GARCÍA MAYNAR y ESTEVE ARNAL, 2007; QUINTAO, 2007). A esta reivindicación en clave económica ya justificada, hemos de adicionar -sin pretensiones exhaustivas- un conjunto de consistentes argumentos jurídicos y de política legislativa, como los que siguen: Primero, el reconocimiento legislativo de las cláusulas sociales a favor de las EI en Derecho comunitario y nacional (v. infra). Segundo, su contribución a la consecución de los valores y los principios constitucionales -comunitarios y nacionales, de nuevo- como la dignidad personal ${ }^{36}$, el derecho al trabajo y la igualdad sustancial. Tercero, el ejemplo y la buena práctica en el mercado de unas Administraciones públicas que admiten y aplican, esto es, que hacen reales los criterios sociales en su demanda de bienes y servicios. Cuarto, las cláusulas sociales representan un complemento y un impulso para el modelo social europeo $^{37}$, para unas economías sociales de mercado altamente competitivas y, en especial, para las políticas sociales y las políticas activas de empleo. Y, quinto, estos criterios sociales en la contratación pública contribuyen tanto al sostenimiento del Estado social, como a la

\footnotetext{
35 Abreviaturas que corresponden a la denominación de la Federación de Asociaciones Empresariales de Empresas de Inserción (vid su web corporativa www.faedei.org). En el contenido de esta web ocupa un importantísimo lugar la materia de las cláusulas sociales.

${ }^{36}$ En línea con la Declaración Universal de Derechos Humanos (Asamblea General ONU, 10.12.1948), el art. 10 CE sitúa a la "dignidad humana" y "los derechos inviolables que le son inherentes" como "fundamento del orden político y de la paz social”. La Carta de los Derechos Fundamentales de la Unión Europea va más allá, pues su primer artículo lleva por título "Dignidad humana" y establece: "La dignidad humana es inviolable. Será respetada y protegida”.

${ }^{37}$ El art. 2 Tratado de la Unión Europea (TUE) dispone: "La Unión se fundamenta en los valores de respeto de la dignidad humana, libertad, democracia, igualdad, Estado de Derecho y respeto de los derechos humanos, incluidos los derechos de las personas pertenecientes a minorías. Estos valores son comunes a los Estados miembros en una sociedad caracterizada por el pluralismo, la no discriminación, la tolerancia, la justicia, la solidaridad y la igualdad entre mujeres y hombres". Por su parte, el art. 3.3 TUE dibuja un horizonte socioeconómico con, entre otros, estos elementos: "una economía social de mercado altamente competitiva, tendente al pleno empleo y al progreso social” y "la Unión combatirá la exclusión social y la discriminación y fomentará la justicia y la protección sociales". Lo que está pendiente es la vigencia real o social de estos mandatos. El Tratado de Funcionamiento de la Unión Europea (TFUE) desarrolla las competencias comunitarias sobre la política social (arts. 151 a 161), entre cuyos objetivos están el fomento del empleo, de la mejora de las condiciones de trabajo, de una protección social adecuada y "la lucha contra las exclusiones” [v. art. $151 \mathrm{y}$ 153.1 letras h) y j)].
} 
incentivación de la innovación social para el desarrollo y la responsabilidad social de las empresas.

Las instituciones comunitarias han reconocido, en fecha reciente, la importancia y la utilidad de los criterios sociales en la contratación pública en el marco de la Estrategia Europa 2020 (subtitulada, recordémoslo, "para un crecimiento inteligente, sostenible e integrador"). Entre las medidas clave para la mejora del entorno jurídico propuestas por la Comisión Europea figura la materia de la contratación pública pues se ha demandado, como reconoce la Comisión, (sic) “que las Directivas deberían hacer más explícita la posibilidad de recurrir a criterios sociales o medioambientales en los contratos públicos” "38. Pero, la Comisión no es precisamente el motor de la innovación social para el desarrollo en la Unión Europea, de ahí que en su citada Propuesta de Reglamento de un Programa para el Cambio y la Innovación Sociales limita sus objetivos de promoción del empleo y la inclusión social a medidas de financiación a favor de personas en situación o riesgo de exclusión social, microempresas y empresas sociales (v. sus arts. 22 a 28). Un abismo entre la realidad y las medidas para transformarla, sin duda.

Por el contrario, el CESE apuesta decididamente por las medidas favorables a que las empresas sociales tengan un mayor acceso a los contratos públicos, reconoce la trascendencia de la jurisprudencia comunitaria en la promoción de estos criterios sociales y anima a la Comisión a que sigua "decididamente el camino emprendido"39.

\footnotetext{
${ }^{38}$ Vid la citada Comunicación "Iniciativa a favor del emprendimiento social. Construir un ecosistema para promover las empresas sociales en el centro de la economía y la innovación sociales". Causa rubor -por no subir el tono de la adjetivación- la manera en que la Comisión Europea deforma a la baja -jibariza o ningunea- esta demanda. La medida clave $\mathrm{n}^{\circ} 10$ prevista por esta Comunicación tiene este tenor: "En el marco de la reforma de la contratación pública, dar mayor valor al elemento de la calidad en la adjudicación de los contratos, sobre todo en el caso de los servicios sociales y sanitarios, y estudiar cómo podrían tenerse en cuenta las condiciones de trabajo de las personas que participan en la producción de los bienes y servicios del contrato, garantizando siempre el pleno respeto de los principios del Tratado sobre la no discriminación, la igualdad de trato y la transparencia" (ibidem, p. 10-11). Conviene indicarlo con claridad: la Comisión Europea, al dictado de los Estados más influyentes, tiene una mirada y unas propuestas neoliberales (PANIAGUA ZURERA, 2011-a), aunque en sus declaraciones no comparta la equivocada y antisocial austeridad expansiva.

${ }^{39}$ Vid su citado Dictamen sobre la Comunicación de la Comisión "Iniciativa en favor del emprendimiento social" (23.05.2012). Y, en la misma línea se había pronunciado en su también citado Dictamen exploratorio sobre "Espíritu empresarial social y las empresas sociales" (26.10.2011). La documentación citada puede consultarse en www.europa.eu.
} 


\section{C) Las cláusulas sociales en la contratación pública en el Derecho comunitario}

Las cláusulas sociales en la contratación pública, en cuanto instrumentos de discriminación positiva a favor del empleo y la inclusión social, tienen plena acogida en el modelo social europeo, digamos en lo estructural, y en la Estrategia Europa 2020, esto es, en lo coyuntural (VALLECILLO GÁMEZ y MOLINA NAVARRETE, 2008; PANIAGUA ZURERA, 2011-a). Las instituciones comunitarias y sus Estados miembros encuentran un decidido impulso en el Derecho comunitario originario (el TUE y el TFUE, así como en la Carta de los Derechos Fundamentales de la Unión Europea) para sus medidas legislativas a favor de los desempleados excluidos. Ha quedado muy superada, en este ámbito debe entenderse, la perspectiva neoliberal de la Comisión Europea cuando sólo admitía las cláusulas o criterios sociales en las condiciones de ejecución de los contratos públicos ${ }^{40}$.

En esta Comunicación de octubre de 2001, la Comisión recuerda que "la interpretación del Derecho comunitario corresponde en última instancia, y en todos los casos, al Tribunal de Justicia Europeo”. No exageramos si afirmamos que el mayor impulso a los criterios sociales en la contratación pública armonizada se debe a la sensibilidad (social) y la valentía (jurídica) del Tribunal de Justicia de la Comunidad Europea (hoy, de la Unión Europea) (TJCE o TJUE). En la sentencia de su Sala Cuarta de 20 de septiembre de 1988 (caso Gebroeders Beetjes BV contra los Países Bajos, asunto 31/87) admitió, en contra de las alegaciones de la Comisión Europea, la entrada en juego de las cláusulas sociales en la fase de adjudicación del contrato público. Interpretación que ha ratificado, de nuevo contra el criterio de la Comisión, en su sentencia del Pleno de 26 de septiembre de 2000 (caso Comisión contra República Francesa, Région Nord-Pas-de-Calais, asunto C-225-98). En esta última sentencia el Alto Tribunal tuvo que recordar a la Comisión Europea que "la condición de contratar a parados de larga duración, sobre la que versaba dicho asunto [caso Gebroeders Beetjes BV], había servido de base para la exclusión de un licitador, por lo que sólo podía constituir un criterio de adjudicación del contrato” (apartado 52). En suma, la jurisprudencia comunitaria ni pone en duda la conformidad con el Derecho comunitario de las cláusulas sociales en la contratación del sector público, ni las limita a la fase de ejecución del contrato como insiste la Comisión y silencia la Directiva 2004/18/CE. Lo que ha realizado el TJUE es una

\footnotetext{
${ }^{40}$ Vid su Comunicación interpretativa sobre la legislación comunitaria de contratos públicos y las posibilidades de integrar aspectos sociales en dichos contratos, COM (2001) 566 final, de 15 de octubre de 2001. La documentación citada puede consultarse en www.europa.eu.
} 
delimitación de los términos o los contenidos de estas cláusulas para su adecuación al Derecho comunitario (p. ej., el respeto de los principios fundamentales del Derecho comunitario, la publicidad y la no concesión al agente adjudicador de un poder de decisión incondicional para seleccionar la oferta económicamente más ventajosa).

Los considerandos de la Directiva 2004/18/CE admiten las cláusulas sociales como criterios de adjudicación (Considerandos 1 y 46$)^{41}$. Su articulado regula expresamente las cláusulas sociales en la ejecución del contrato (v. art. 26) y, a falta de acuerdo político, silencia los elementos o contenidos directamente sociales como criterios de adjudicación de la oferta económicamente más ventajosa (v. art. 53). Pero, sí admite, para la selección o determinación de esa oferta económicamente más ventajosa, la aplicación de "los criterios vinculados al objeto del contrato público", y cita "por ejemplo", luego la enumeración no es taxativa, "la calidad, el precio, el valor técnico, las características estéticas y funcionales, las características medioambientales, el coste de funcionamiento, la rentabilidad, el servicio posventa y la asistencia técnica, la fecha de entrega y el plazo de entrega o de ejecución”. Como la jurisprudencia comunitaria ya ha admitido las cláusulas sociales como criterios de adjudicación, resulta sumamente es fácil -en términos jurídicos- su integración en la interpretación sistemática de la citada directiva y en los sistemas jurídicos de los Estados miembros.

\section{D) Los criterios sociales en los contratos del sector público en el ordenamiento} jurídico español

En el ordenamiento jurídico español el citado TRLCSP, como hacía el texto refundido precedente, traspone la Directiva 2004/18/CE en materia de criterios sociales en la ejecución del contrato, y supera el aparente silencio del articulado esta directiva comunitaria respecto a las cláusulas sociales como criterios de adjudicación en la contratación pública.

El art. 118 TRLCSP (Condiciones especiales de ejecución del contrato) permite ("podrán establecer", establece) que el órgano adjudicador pueda incluir condiciones

\footnotetext{
${ }^{41}$ El Considerando 1 afirma que la Directiva 2004/18/CE es una refundición de la normativa precedente y que esta directiva "está basada en la jurisprudencia del Tribunal de Justicia, en particular la relativa a los criterios de adjudicación”. Y, en el extenso Considerando 46 se afirma que "el poder adjudicador podrá regirse por criterios destinados a satisfacer exigencias sociales que, en particular, respondan a necesidades -definidas en las especificaciones del contrato- propias de las categorías de población especialmente desfavorecidas a las que pertenezcan los beneficiarios/usuarios de las obras, suministros y servicios que son objeto del contrato”.
} 
especiales de ejecución siempre que respete los principios del Derecho comunitario. Estas condiciones pueden referirse, entre otras, "a consideraciones de tipo social, con el fin de promover el empleo de personas con dificultades particulares de inserción en el mercado laboral” (art. 118.1, que es legislación básica estatal ex art. 149.1.18 $\left.{ }^{\mathrm{a}} \mathrm{CE}\right)^{42}$.

Por su parte el art. 150 TRLCSP, bajo la rúbrica de "Criterios de valoración de las ofertas”, esto es, en la fase de la adjudicación del contrato público, ordena que para determinar "la oferta económicamente más ventajosa deberá atenderse a criterios directamente vinculados al objeto del contrato". Nuestra legislación en materia de contratación del sector público incorpora una enumeración ejemplificativa, similar a la de la Directiva 2004/18/CE (v. supra), de los referidos criterios vinculados directamente al objeto del contrato. Entre los ejemplos figuran expresamente los criterios sociales, que se describen como las características (sic) "vinculadas con la satisfacción de exigencias sociales que respondan a necesidades, definidas en las especificaciones del contrato, propias de las categorías de población especialmente desfavorecidas a las que pertenezcan los usuarios o beneficiarios de las prestaciones a contratar" (art. 150.1, que es asimismo legislación básica estatal ex art. 149.1.18 ${ }^{\mathrm{a}} \mathrm{CE}$ ). El TRLCSP exige que los criterios que vayan a servir de base para la adjudicación del contrato "se determinarán por el órgano de contratación y se detallarán en el anuncio, en los pliegos de cláusulas administrativas particulares o en el documento descriptivo" (art. 150.2 párr. primero). Una vez determinados los criterios vinculados al objeto del contrato, el legislador español convierte estos criterios en vinculantes para la valoración de la oferta económica más ventajosa por parte del órgano de contratación: “deberá atenderse”, dispone (v. supra).

Dada la razonable insistencia -comunitaria y nacional- en que las cláusulas sociales estén directamente vinculadas al objeto del contrato público, resulta totalmente aconsejable que en el pliego de condiciones generales o particulares, según los casos, cuando se delimite el objeto del contrato público figure una referencia directa y expresa, por lo que ahora nos interesa, a la inserción sociolaboral de colectivos especialmente desfavorecidos.

\footnotetext{
${ }^{42}$ Como recuerda la D. F. $2^{\mathrm{a}} .3$ TRLCSP (Títulos competenciales), estas disposiciones que comentamos son legislación básica estatal sobre contratos administrativos y, en consecuencia, "son de aplicación general a todas las Administraciones Públicas y organismos y entidades dependientes de ellas”.
} 
El reconocimiento de los criterios sociales como condiciones para la adjudicación de contratos públicos a favor de las $\mathrm{EI}^{43}$, va más allá. El TRLCSP, superando la timidez de la comentada LEI amplía, dentro siempre de su carácter voluntario o potestativo para nuestras Administraciones públicas, las cláusulas sociales en la contratación del sector público a favor de las EI, en los términos que siguen: "Igualmente podrá establecerse la preferencia en la adjudicación de contratos, en igualdad de condiciones con las que sean económicamente más ventajosas, para las proposiciones presentadas por las empresas de inserción reguladas en la Ley 44/2007, de 13 de diciembre, para la regulación del régimen de las empresas de inserción, que cumplan con los requisitos establecidos en dicha normativa para tener esta consideración” (D. A 4 $4^{\mathrm{a}}$. 3 TRLCSP, que es legislación básica estatal ex art. 149.1.18 ${ }^{\mathrm{a}}$ CE). En consecuencia, si existe sensibilidad social (y hacia lo social) y voluntad política (y de servicio al interés general) nuestras Administraciones públicas deben establecer en sus pliegos de contratación que, a igualdad de condiciones con las ofertas económicamente más ventajosas, el contrato del sector público se adjudique al empresario de inserción. Es oportuno reiterar que incluso la (endiosada) eficiencia económica inclina a adoptar esta decisión, pues lo que la EI obtiene del mercado se transforma como indicamos en un doble ingreso público: primero, como ingresos fiscales y sociales (los impuestos y las cotizaciones sociales) y, segundo, como ahorro de gasto social (las prestaciones sociales contributivas o no). Este círculo (virtuoso) se cierra si nuestros poderes públicos quieren hacer real (nos referidos ahora a la realidad y a la experiencia jurídica), como están obligados ex art. 9.1 CE, la supremacía material de nuestra Norma Fundamental (v. el Preámbulo de nuestra Constitución y, ad exemplum, sus arts. 1.1, 9.2, 10, 35, 38, 40 y 129.2 CE).

\section{CONCLUSIONES}

Primera.- Dentro de los avances en innovación social tiene singularidad la que hemos denominado como innovación social para el desarrollo que se caracteriza por su orientación hacia la satisfacción de necesidades humanas básicas, por el empleo intensivo de capital humano y relacional y por su apertura y ofrecimiento a la difusión e imitación como buena práctica.

\footnotetext{
${ }^{43}$ Como también se hace en favor de personas con discapacidad, de entidades sin ánimo de lucro o las organizaciones reconocidas como de comercio justo (v. DD. AA. $4^{\mathrm{a}}$ y $5^{\mathrm{a}}$ TRLCSP).
} 
Segunda.- Esta modalidad de innovación social sirve, además de a un proyecto específico o identitario, a fines sociales y de interés general. Se ubica en la intersección de la Economía, el Derecho, la Política y la Ética. Pese a las dificultades de delimitación que aún presenta, la innovación social para el desarrollo ha captado la atención de la Unión Europea y de sus Estados miembros en sus programas y estrategias de lucha contra la pobreza y la exclusión social.

Tercera.- La globalización económica neoliberal está concentrando la riqueza en manos de un reducido grupo de personas pertenecientes a las élites económicas y políticas y, como consecuencia, está socializando y agudizando las dinámicas de exclusión social en las sociedades del primer mundo. En un escenario más propio de episodios de darwinismo social que del normal funcionamiento de unos Estados democráticos y sociales, la Unión Europea y sus Estados demandan la ayuda de la sociedad en defensa de las políticas sociales, las políticas activas de empleo y las de inclusión social, en especial, a favor de personas en situación o riesgo de exclusión social.

Cuarta.- A esta petición de ayuda responden las empresas de inserción y sus entidades (no lucrativas) promotoras. España ha sido pionera con la aprobación de una ley estatal que define y caracteriza -de ahí nuestro interés por el fin que deben perseguir- a las empresas de inserción. Por el contrario, lo que no ha hecho ni el Legislativo ni el Ejecutivo estatal es acompañar este régimen sustantivo (y laboral) con las necesarias medidas de fomento o promoción pública, como las demandadas por el sector de las EI desde su surgimiento a mediados de los ochenta del pasado siglo. Nuestros poderes públicos tienen pendiente el reconocimiento efectivo o sustancial de la utilidad o valor social añadido (y, por supuesto, que debe ser acreditado) de las EI. Dado su servicio a fines sociales y de interés general, la consecuencia obligada -en términos económicos y jurídicos- es la promoción pública de las externalidades positivas que generan estos nuevos empresarios de la economía social.

Quinta.- Toda empresa demanda mercado para desarrollar su actividad y para generar utilidades. Las EI demandan, con argumentos de racionalidad económica y de legitimidad jurídica y de legalidad, mercados sociales para, por un lado, desarrollar su actividad económica que genera riqueza, valor o utilidades y, por otro, cumplir su fin social y de interés general: la inserción sociolaboral de personas desempleadas y en situación o riesgo de exclusión social. La organización jurídico-política y el sistema económico protegido por la 
Unión Europea y sus Estados (los Estados democráticos y sociales y las economías sociales de mercado altamente competitivas, según el TUE) no pueden negar medidas de discriminación positiva para que las EI, normalmente pymes, puedan tener acceso al mercado de la contratación pública. Así lo reconoce ejemplarmente la jurisprudencia comunitaria y la legislación española en materia de contratos del sector público. Con todo, la Comisión Europea, y las tensiones entre los Estados miembros, han tratado de reducir o minimizar el alcance de estas cláusulas sociales, lo que es contrario al Derecho comunitario.

Sexta.- Hemos de llamar la atención sobre los problemas de conceptuación y delimitación que siguen aquejando al tercer sector o economía social, pues brotan en cualquier investigación. No podemos minusvalorar los avances: los elogiables esfuerzos realizados desde los centros de investigación (p. ej., CIRIEC), el reconocimiento de la economía social en el soft law comunitario, en el derecho derivado comunitario y en las legislaciones nacionales (con la pionera Ley española 5/2011, de economía social). Pero, también tiene fuerza la teorización anglosajona de las non profit. El problema estalla si se pretende reducir el debate a una mera discusión terminológica y de ámbito subjetivo. Ambos fenómenos y movimientos son innovaciones sociales para el desarrollo, y como tales merecen reconocimiento y promoción, y debieran colaborar. No obstante, no son iguales la historia, los valores y el proyecto de la economía social, que los de las non profit organizations. Debemos ser conscientes, para pensar y actuar con sentido. Algún indicio y reflexión se aportan en el texto.

\section{BIBLIOGRAFÍA}

AA. VV. (2011). Reacciona, Madrid: Aguilar, 161 p. ISBN: 978-84-03-10200-2.

AGUILERA IZQUIERDO, R. (2009). El régimen jurídico de las empresas de inserción, Pamplona: Thomson-Civitas, 160 p. ISBN: 978-84-470-3138-2.

ÁLVAREZ VEGA, Mª L. (1999). Las empresas de inserción social como nueva forma de organización empresarial. Especial referencia a su régimen jurídico, Revista CiriecEspaña, no 31 , junio, p. 47-84.

CALVO BERNARDINO, A. y PAÚL GUTIÉRREZ, J. (2000). El proceso de globalización y la intervención del Estado en la Economía, Revista de Hacienda Pública Española, $\mathrm{n}^{\circ}$ 152, p. 21-27. 
CHAVES, R. y MONZÓN, J. L. (dir.) (2007), La Economía Social en la Unión Europea, Informe elaborado por el CIRIEC para el Comité Económico y Social Europeo, CESE 97/2007 Gr. III, 131 p.

CHAVES, R. y MONZÓN, J. L. (2008). Panorama de investigación en Economía Social, Revista de Estudios de Economía Aplicada, no 26-1, abril, p. 7-24.

CONSEJO ECONÓMICO Y SOCIAL (2007). Dictamen sobre el Anteproyecto para la regulación del régimen de las empresas de inserción, Sesión ordinaria del Pleno de 20 de junio de 2007, Madrid: CES.

DEFOURNY, J., FAVREAU, L. y LAVILLA, J. L. (dir.) (1997), Inserción social y nueva economía social. Un balance internacional, Valencia: Ciriec-España, 389 p. ISBN: 8495003-02-3.

DWORKIN, R. (1995). Los derechos en serio, trad. M. Guastavino, Barcelona: Ariel, 509 p. ISBN: 84-344-1508-9.

FONT GALÁN, J. I. (1987). Constitución económica y derecho de la competencia, Madrid: Tecnos, 345 p. ISBN: 978-84-309-1435-7. Prólogo de Manuel OLIVENCIA RUIZ.

FONT OPORTO, P. (2012). Ruptura del consenso socialdemócrata y crisis del modelo de Estado, Revista de Fomento Social, no 266, abril-junio, p. 211-250.

FUNDACIÓ CAIXA CATALUNYA (2008). Informe de la inclusión social en España 2008, Barcelona: Fundació Caixa Catalunya, 251 p. ISBN: 978-84-612-5816-1.

FUNDACIÓN FOESSA (2013). Desigualdad y derechos sociales. Análisis y perspectivas 2013, Madrid: Fundación FOESSA y Cáritas Española, 76 p. ISBN: 978-84-8440-556-6.

GARCÍA MAYNAR, A. y ESTEVE ARNAL, M. (2007). Las empresas de inserción en España: normativa y características, Revista Ciriec-España, $\mathrm{n}^{\circ} 59$, octubre (monográfico), p. $153-178$.

GARCÍA MAYNAR, A. (2007). El momento actual de las empresas de inserción, un momento histórico, Revista Ciriec-España, no 59, octubre (monográfico), p. 7-32.

GEORGE, S. (2004). Otro mundo es posible si ..., trad. B. Wang, Barcelona: Icaria-Intermón Oxfam, 231 p. ISBN: 978-84-8452-277-5.

GIMÉNEZ MARÍN, J. (dir.) (2010), Anuario del Tercer Sector de Acción Social en España (2010), Madrid: Fundación Luis Vives, 404 p. D.L.: M-43562-2010.

LEMES ZABALEGUI, S. (2006). Cláusulas sociales. Contratación pública e inserción sociolaboral, Bilbao: Asociación Berriztapen, 124 p. 
LÓPEZ-ARANGUREN MARCOS, L. Ma (2002). Las empresas de inserción en España. Un marco de aprendizaje para la inserción laboral, Madrid: Consejo Económico y Social, 280 p. ISBN: 978-84-8188-169-1.

HAYEK, F. A. (2006). Derecho, legislación y libertad. Una nueva formulación de los principios liberales de la justicia y de la economía política, Madrid: Unión Editorial, 556 p. ISBN: 84-7209-428-6.

HESSEL, S. (2011). ¡Indignaos! Un alegato contra la indiferencia y a favor de la insurrección pacífica, trad. T. Moreno Lanaspa, Madrid: Destino, 64 p. ISBN: 978-84233-4471-0.

MARCUELLO SERVOS, CH. (2007). Las empresas de inserción y sus retos, Revista de Economía Social, n 36, marzo, p. 36-43.

MARTÍN PUEBLA, E. (2007). Empresas de inserción y política de empleo, Revista Aranzadi Social, $\mathrm{n}^{\mathrm{o}} 22$, p. 1-17.

MELIÁN NAVARRO, A., CAMPOS CLIMENT, V. y SANCHIS PALACIO, J. R. (2011). Emprendimiento social y empresas de inserción en España. Aplicación del método Delphi para la determinación del perfil del emprendedor y las empresas sociales creadas por emprendedores, REVESCO, Revista de Estudios Cooperativos, n ${ }^{\circ} 106$, p. 150-172.

MORALES GUTIÉRREZ, A. C., ARIZA MONTES, J. A. y MUÑIZ RODRÍGUEZ, N. M. (2012). El emprendedor social y el e-empowerment de las redes virtuales, Revista CiriecEspaña, $\mathrm{n}^{\mathrm{o}} 75$, agosto, p. 153-177.

MORALES GUTIÉRREZ, A. C. (1991). La cooperativa como realidad social, ideológica y económica, Córdoba: Publicaciones ETEA (Colección Tesis Doctorales), 137 p. ISBN: 84-86785-08-1. Prólogo de Adolfo RODERO FRANGANILLO.

MORALES GUTIÉRREZ, A. C. (1994). Análisis de las organizaciones. Fundamentos, diseño y aplicaciones, Córdoba: Publicaciones ETEA, 413 p. ISBN 84-86785-21-9. Prólogo de Manuel PÉREZ YRUELA.

MORALES GUTIÉRREZ, A. C. (2000). Arquitectura de sistemas organizativos, Córdoba: Publicaciones ETEA, 404 p. ISBN: 84-86785-47-2.

MORALES GUTIÉRREZ, A. C. (2006). Dirigir una organización no lucrativa: un equilibrio difícil entre eficacia, eficiencia y coherencia. En: AA. VV. dirigidos por J. JIMÉNEZ ESCOBAR y A. C. MORALES GUTIÉRREZ, Dirección de entidades no lucrativas. Marco jurídico, análisis estratégico y gestión, Pamplona: Aranzadi-Civitas, p. 253-295. ISBN: 84-470-2542-X.

REVESCO No 112 - Extraordinario en Homenaje al Profesor Alfonso Carlos MORALES GUTIÉRREZ - ISSN: 1885-8031 - www.ucm.es/info/revesco 
MORALES GUTIÉRREZ, A. C. (2008). Innovación social: una realidad emergente en los procesos de desarrollo, Revista de Fomento Social, no 251, julio-septiembre, p. 411-444.

MORALES GUTIÉRREZ, A. C. (2009). Claves para comprender la innovación social. En: AA. VV. La innovación social, motor de desarrollo de Europa, Sevilla: Socialinnova, pp. 13-38.

NAVARRO, V., TORRES LÓPEZ, J. y GARZÓN ESPINOSA, A. (2011). Hay alternativas. Propuestas para crear empleo y bienestar social en España, Madrid: ATTAC España, 221 p. ISBN: 978-84-95363-94-7. Prólogo de Noam CHOMSKY.

QUINTAO, C. (2007). Empresas de inserción y empresas sociales en Europa, Revista CiriecEspaña, $\mathrm{n}^{\circ} 59$, p. 35-57.

PANIAGUA ZURERA, M. (2008). Las empresas de inserción en la Ley estatal 44/2007, de 13 de diciembre, reguladora de las empresas de inserción, Revista Cuadernos de Derecho y Comercio, ${ }^{\circ}$ 49, junio, p. 9-59.

PANIAGUA ZURERA, M. (2011). Las empresas de la economía social. Más allá del comentario a la Ley 5/2011, de economía social, Madrid: Marcial Pons, 2011-a, 317 p. ISBN: 978-84-9768-921-2. Prólogo de Juan I. FONT GALÁN.

PANIAGUA ZURERA, M. (2011). Los empresarios de la economía social y su valor social añadido (del soft law comunitario a la precursora ley española de economía social), Revista de Fomento Social, no 263, julio-septiembre, 2011-b, p. 359-399.

PÉREZ LUÑO, A. E. (2011). Teoría del Derecho. Una concepción de la experiencia jurídica, 10a ed., Madrid: Tecnos, 253 p. ISBN: 978-84-309-5342-4.

REAS Euskadi (2010), Cláusulas sociales, herramientas al servicio de la inserción sociolaboral, Bilbao: REAS Euskadi, 30 p. D. L.: BI-3335-2010.

RODRIK, D. (2012). La paradoja de la globalización. Democracia y futuro de la economía mundial, trad. Ma D. Crispín Sanchis, Barcelona: Antoni Bosch, 364 p. ISBN: 978-8495348-61-6.

ROJO TORRECILLA, E. (1999-2000). Apuntes sobre el marco normativo de las empresas de inserción, Revista de Documentación Social, nº 117-118, p. 103-123.

RUIZ ROQUEÑI, M., RETOLAZA AVAlOS, J. L. y MUGARRA ElORRIAGA, A. (2007). Cláusulas sociales y mercados tutelados: herramientas para la competitividad de las empresas de inserción, Revista Ciriec-España, nº 59, octubre, p. 123-151.

SANDEL, M. J. (2013). Lo que el dinero no puede comprar. Los límites morales del mercado, trad. J. Chamorro Mielke, Barcelona: Debate, 254 p. ISBN: 978-84-9992-232-4. 
SEN, A. (2010). La idea de la justicia, trad. H. Valencia Villa, Madrid: Taurus, 499 p. ISBN: 978-84-306-0686-3.

SOTELO, I. (2010). El Estado social. Antecedentes, origen, desarrollo y declive, Madrid: Trotta, 425 p. ISBN: 978-84-9879-143-3.

VALLECILLO GÁMEZ, Ma R. y MOLINA NAVARRETE, C. (2008). Empresas de inserción y mercados de trabajo inclusivos. Nuevo marco regulador y modelos de gestión, Granada: Comares, 252 p. ISBN: 978-84-9836-382-1.

VECIANA BOTET, F. (coord.) (2007). Las empresas de inserción en España, Barcelona: Fundació Un Sol Món de Caixa de Catalunya, 145 p. ISBN: 978-84-612-0453-3. 